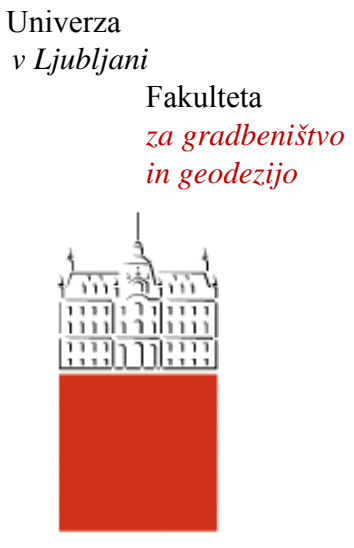

Jamova cesta 2

1000 Ljubljana, Slovenija

http://www3.fgg.uni-lj.si/

\section{DRUGG - Digitalni repozitorij UL FGG http://drugg.fgg.uni-lj.si/}

Ta članek je avtorjeva zadnja recenzirana različica, kot je bila sprejeta po opravljeni recenziji.

Prosimo, da se pri navajanju sklicujte na bibliografske podatke, kot je navedeno:
University
of Ljubljana

Faculty of Civil and Geodetic Engineering

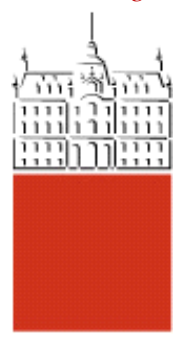

Jamova cesta 2 SI - 1000 Ljubljana, Slovenia http://www3.fgg.uni-lj.si/en/ DRUGG - The Digital Repository
http://drugg.fgg.uni-lj.si//

This version of the article is author's manuscript as accepted for publishing after the review process.

When citing, please refer to the publisher's bibliographic information as follows: 


\title{
Geosynthetic-encased stone columns: Analytical calculation model
}

\author{
Boštjan Pulko, Bojan Majes, Janko Logar
}

Corresponding author:

Boštjan Pulko

University of Ljubljana, Faculty of Civil and Geodetic Engineering, Jamova 2, 1000 Ljubljana, Slovenia

E-mail: bostjan.pulko@,fgg.uni-lj.si

Tel.: +3861 4768523, fax: +38614250681

\section{Bojan Majes}

University of Ljubljana, Faculty of Civil and Geodetic Engineering, Jamova 2, 1000 Ljubljana, Slovenia

E-mail: bojan.majes@,fgg.uni-lj.si

Tel.: +3861 4768522, fax: +3861 4250681

\section{Janko Logar}

University of Ljubljana, Faculty of Civil and Geodetic Engineering, Jamova 2, 1000 Ljubljana, Slovenia

E-mail: janko.logar@,fgg.uni-li.si

Tel.: +3861 4768526, fax: +38614250681

\begin{abstract}
This paper presents a newly developed design method for non-encased and encased stone columns. The developed analytical closed form solution is based on previous solutions, initially developed for non-encased columns and for non-dilating rigid-plastic column material. In the present method, the initial stresses in the soil/column are taken into account, with the column considered as an elasto-plastic material with constant dilatancy, the soil as an elastic material and the geosynthetic encasement as a linearelastic material. To check the validity of the assumptions and the ability of the method to give reasonable predictions of settlements, stresses and encasement forces, comparative elasto-plastic finite element analyses have been performed. The agreement between the two methods is very good, which was the reason that the new method was used to generate a parametric study in order to investigate various parameters, such as soil/column parameters, replacement ratio, load level and geosynthetic encasement stiffness on the behaviour of the improved ground. The results of this study show the influence of key parameters and provide a basis for the rational predictions of settlement response for various encasement stiffnesses, column arrangements and load levels. The practical use of the method is illustrated through the design chart, which enables preliminary selection of column spacing and encasement stiffness to achieve the desired settlement reduction for the selected set of the soil/column parameters.
\end{abstract}

Keywords: Soil improvement, Stone columns, Geosynthetic encasement, Settlement prediction, Elasto-plastic solution 


\section{Introduction}

Stone columns or granular piles are frequently used to stabilize soft clays and silts and loose silty sands with large amount of fines. For low-rise buildings, highway facilities, storage tanks, embankments, bridge abutments and other structures that can tolerate some settlements stone columns are one of the most frequently used methods of support due to their low cost, effectiveness and ease of installation. The beneficial effects of stone columns are increased stiffness, reduced settlements, increased time rate of settlements, increased shear strength and reduction of the liquefaction potential of soft ground (Barksdale and Bachus, 1983). As the construction and use of the conventional stone columns in very soft soil with low undrained shear strength are almost impossible due to insufficient lateral support of the soil, the problem can be solved by encasing the column material in geosynthetics. The foundation system initially introduced as geotextile encased columns (GECs) has been adopted successfully and is well established in engineering practice (Raithel and Kempfert, 2000; Raithel et al., 2002). Similar concepts based on geogrid encasement as a more robust and perhaps stiffer alternative to geotextile have more recently been introduced and investigated (Sivakumar et al., 2004, Malarvizhi and Ilamparuthi, 2007; Murugesan and Rajagopal, 2006, 2007, 2010; Yoo and Kim, 2009; Araujo et. al., 2009; Gniel and Bouazza, 2009, 2010) to demonstrate the effectiveness of geosynthetic encasement and to improve design methods.

The available methods for the design of foundations resting on soft soil stabilised by a large number of end-bearing stone-columns can be classified as either approximate methods with important simplifying assumptions or sophisticated methods based on complex modelling using finite element method or homogenization techniques. Most of approximate analytical solutions assume infinitely wide, loaded area with end-bearing stone columns having constant diameter and spacing, where the stone column and the surrounding soil are treated in axial symmetric conditions. This approach is commonly known as a unit cell concept (Priebe, 1976; Aboshi et al., 1979) and has been adopted by several researchers for the analysis of traditional and encased stone columns.

A number of methods are available for the analysis of traditional non-encased stone columns. First suggestions were based on elastic approach (Aboshi et al., 1979; Balaam and Booker, 1981). It was shown that elastic methods may easily overestimate the effects of stone columns on settlement reduction (Balaam and Booker, 1985). Therefore elasto-plastic analytical methods were introduced, where the problem was idealized by assuming that the stone column is in a triaxial stress state and perhaps yielding, that there is no shear stress at the stone-soil interface and that there is no yielding in the soil. These common assumptions have been implemented in a number of methods where traditional non-encased stone column is considered to be in a state of plastic equilibrium and under a triaxial stress state (Priebe, 1976; Van Impe and De Beer, 1983; Balaam and Booker, 1985; Van Impe and Madhav, 1992; Pulko and Majes, 2005, 2006).

Not so many analytical methods have been developed for the analysis of encased stone columns. Where a large number of stone columns is used to enhance the ability of soft ground to support an embankment or a raft foundation, the design method presented by Reithel and Kempfert (2000) is probably the most popular and accepted one. The 
method is based on the unit cell concept where the column is considered as rigid-plastic, with infinite modulus of elasticity, yield limit at the active state and plastic deformation at constant volume (zero dilatancy). The geosynthetic encasement is considered as a linear-elastic material and for the soil behaviour some assumptions of semi-empirical nature are made: the horizontal stresses in the soil are linearly proportional to the vertical stresses through preselected lateral stress coefficients. The guidelines for the design of geotextile encased columns presented by Murugesan and Rajagopal (2007) are also well known and accepted. In their method the bearing support from the soil is conservatively ignored and thus, the method focuses more on the performance of a stone column acting as a pile, with external load applied only on the column top and not on surrounding soil.

The objective of this paper is to present an extension of approaches presented by Balaam and Booker (1985) and Reithel and Kempfert (2000) in a form of analytical closed-form elasto-plastic solution. The developed method takes into account elastoplastic behaviour of the column material with confined yielding according to the Rowe stress-dilatancy theory (Rowe, 1962) and gives reasonable prediction of improved ground behaviour for non-encased and encased stone columns.

\section{Calculation model}

If stone-columns are regularly distributed, a regularly shaped area around the stonecolumn may be considered as a "unit cell", consisting of stone-column and the surrounding soft soil in a zone of influence (Fig. 1). To simplify the analysis the zone of influence is approximated by a circle with a diameter $d_{e}$ equal to $1.05 \mathrm{~s}, 1.13 \mathrm{~s}$ and $1.29 \mathrm{~s}$, for triangular, square or hexagonal patterns, respectively, where $s$ is the column spacing. The column spacing ratio is defined as $d_{e} / d_{c}$. The ratio between the area of column $A_{c}$ and the area of the zone of influence $A_{e}$ represents the replacement ratio $A_{r}=A_{c} / A_{e}=\left(d_{c} / d_{e}\right)^{2}$.

\section{Fig. 1.}

When loaded, the improved soil will initially deform under undrained conditions, whereas the high drainage capacity of the column material ensures that it deforms almost under drained conditions. If the soil is considered incompressible, then the immediate settlement is negligible compared to the total final settlements (Balaam and Booker, 1985) and will not be considered in the paper.

Beside the "unit cell" concept the following assumptions were taken into account to simplify the problem and to obtain the closed form solution:

- The settlements on the top of the column and the soil under rigid load are equal. Thus, no shear along the soil/column interface is taken into account.

- The top and bottom planes of the unit cell are perfectly smooth.

- The settlements in the bearing strata are neglected.

- The soil remains elastic throughout the range of applied load.

- The column material behaves as elastic-plastic material satisfying the Mohr-Coulomb yield criterion with constant dilation angle $\psi$. 
- Geosynthetic material behaves as elastic material with constant deformation modulus. - First-order strain theory is taken into account.

\subsection{Initial elastic response}

For very small vertical distributed load $q_{A}\left[\mathrm{kN} / \mathrm{m}^{2}\right]$ the initial response of the soil and the column will be elastic. The elastic solution of the "unit cell" for the conventional non-encased stone column was presented by Balaam and Booker (1981) and can easily be extended by taking into account the geosynthetic encasement.

Under uniform distributed load $q_{A}$ applied through rigid raft the end-bearing stonecolumn and the surrounding soil will undergo the same vertical displacement $u_{z}$ and radial displacement $u_{r}$. Thus, at the soil-column interface no slippage is expected between the soil and the granular material. The vertical and radial strains of the stonecolumn are defined as:

$\left\{\begin{array}{l}\varepsilon_{z} \\ \varepsilon_{r}\end{array}\right\}=\left\{\begin{array}{l}u_{z} / H \\ u_{r} / r_{c}\end{array}\right\}$

where $H$ is the height and $r_{c}$ the radius of the stone (granular) column.

The soil surrounding the stone-column can be analysed as a thick cylinder using equation relating vertical and radial strains, $\varepsilon_{z}$ and $\varepsilon_{r}$ at the soil-column interface with vertical and radial stresses in the soil, $\sigma_{z s}$ and $\sigma_{r s}$ (Poulos and Davis, 1974):

$\left\{\begin{array}{l}\varepsilon_{z} \\ \varepsilon_{r}\end{array}\right\}=\frac{1}{C_{3} E_{\text {oed }}}\left[\begin{array}{cc}C_{2} & -C_{1} \\ -k_{0} & 1\end{array}\right]\left\{\begin{array}{c}\sigma_{z s} \\ \sigma_{r s}\end{array}\right\}$

where $E_{\text {oed }}$ is the oedometer modulus of the soil and $C_{1}, C_{2}$ and $C_{3}$ constants defined as:

$C_{1}=\frac{2 k_{0} A_{r}}{1-A_{r}}, \quad C_{2}=\frac{1-2 v_{s}+A_{r}}{\left(1-A_{r}\right)\left(1-v_{s}\right)}, C_{3}=C_{2}-k_{0} C_{1}$

where $v_{s}$ is Poisson's ratio of the soil and $k_{0}=v_{s} /\left(1-v_{s}\right)$.

The stress-strain relationship for the stone-column under triaxial state is given by:

$\left\{\begin{array}{l}\varepsilon_{z} \\ \varepsilon_{r}\end{array}\right\}=\frac{1}{E_{c}}\left[\begin{array}{cc}1 & -2 v_{c} \\ v_{c} & v_{c}-1\end{array}\right]\left\{\begin{array}{l}\sigma_{z c} \\ \sigma_{r c}\end{array}\right\}$

where $\sigma_{z c}$ and $\sigma_{r c}$ represent vertical and horizontal stresses in the stone-column, respectively, and $v_{c}$ is Poisson's ratio of the column.

In contrast to the non-encased column, where the horizontal support of the soil $\sigma_{r s}$ is equal to the horizontal pressure in the column $\sigma_{r c}$, the radial stress difference $\Delta \sigma_{r}$ must be taken by the geosynthetic encasement. The hoop force $F_{R}$ in the elastic encasement, which provides additional lateral support for the column, thus becomes: $F_{R}=\Delta \sigma_{r} r_{c}=\left(\sigma_{r c}-\sigma_{r s}\right) r_{c}=J \varepsilon_{r}$

where $J$ is the stiffness of the encasement. 
Using the above stress-strain relationships (Eq. 2, 4, 5 and 6) and the equilibrium equation:

$$
q_{A}=\sigma_{z c} A_{r}+\sigma_{z s}\left(1-A_{r}\right)
$$

the system of equations can be solved to obtain the elastic vertical strain $\varepsilon_{z}^{e l}$ caused by the applied load $q_{A}$ :

$$
\varepsilon_{z}^{e l}=\frac{q_{A}}{\left(\lambda_{c}+2 G_{c}\right) A_{r}+\left(\lambda_{s}+2 G_{s}\right)\left(1-A_{r}\right)-2 A_{r}\left(\lambda_{c}-\lambda_{s}\right) F}
$$

where $F$ is a constant defined as:

$$
F=\frac{\left(\lambda_{c}-\lambda_{s}\right)\left(1-A_{r}\right)}{2\left[A_{r}\left(\lambda_{s}+G_{s}-\lambda_{c}-G_{c}\right)+\lambda_{c}+G_{c}+G_{s}\right]+\left(1-A_{r}\right)\left(2 G_{s}+\lambda_{s}\right) T}
$$

where $T$ is a dimensionless stiffness of the encasement defined as:

$T=\frac{J}{E_{\text {oed }} r_{c}}$

$\lambda_{s}, G_{s}$ and $\lambda_{c}, G_{c}$ are Lamé's parameters of the soil and the column, respectively, and can be calculated as:

$$
\lambda=\frac{v E}{(1-2 v)(1+v)}, G=\frac{E}{2(1+v)}
$$

where $E$ and $v$ refer to Young's modulus and Poisson's ratio.

For the calculated vertical strain $\varepsilon_{z}^{e l}$ (Eq. 7) the radial elastic strain $\varepsilon_{r}^{e l}$ and stresses in the column and soil become:

$$
\begin{aligned}
& \varepsilon_{r}^{e l}=F \varepsilon_{z}^{e l} \\
& \left\{\begin{array}{l}
\Delta \sigma_{z c} \\
\Delta \sigma_{r c}
\end{array}\right\}=\left[\begin{array}{c}
\lambda_{c}+2 G_{c}-2 \lambda_{c} F \\
\lambda_{c}-2\left(\lambda_{c}+G_{c}\right) F
\end{array}\right]\left\{\varepsilon_{z}^{e l}\right\},\left\{\begin{array}{l}
\Delta \sigma_{z s} \\
\Delta \sigma_{r s}
\end{array}\right\}=\left[\begin{array}{c}
\lambda_{s}+2 G_{s}+2 \lambda_{s} \frac{F A_{r}}{1-A_{r}} \\
\lambda_{s}+\frac{2 A_{r} F}{1-A_{r}}\left(\lambda_{s}+G_{s}+\frac{G_{s}}{A_{r}}\right)
\end{array}\right]\left\{\begin{array}{c}
\left.\varepsilon_{z}^{e l}\right\}
\end{array}\right.
\end{aligned}
$$

with the hoop force $F_{R}$ in the encasement:

$$
F_{R}=J F \varepsilon_{z}^{e l}
$$

The settlement reduction factor $\beta^{e l}$, which is generally used as a measure for the improvement of the ground, is defined as the ratio of settlements or vertical strains of the treated to the untreated ground under widespread load:

$$
\beta^{e l}=\frac{E_{\text {oed }}}{\left(\lambda_{c}+2 G_{c}\right) A_{r}+\left(\lambda_{s}+2 G_{s}\right)\left(1-A_{r}\right)-2 A_{r}\left(\lambda_{c}-\lambda_{s}\right) F}
$$

The stress concentration factors $\eta_{c}^{e l}$ and $\eta_{s}^{e l}$, defined as the ratio between the vertical stresses in the column/soil and load $q_{A}$, are given by:

$$
\eta_{c}^{e l}=\frac{\sigma_{z c}}{q_{A}}=\frac{\lambda_{c}+2 G_{c}-2 \lambda_{c} F}{\left(\lambda_{c}+2 G_{c}\right) A_{r}+\left(\lambda_{s}+2 G_{s}\right)\left(1-A_{r}\right)-2 A_{r}\left(\lambda_{c}-\lambda_{s}\right) F}
$$




$$
\eta_{s}^{e l}=\frac{\sigma_{z S}}{q_{A}}=\frac{\lambda_{s}+2 G_{s}+2 \lambda_{s} \frac{F A_{r}}{1-A_{r}}}{\left(\lambda_{c}+2 G_{c}\right) A_{r}+\left(\lambda_{s}+2 G_{s}\right)\left(1-A_{r}\right)-2 A_{r}\left(\lambda_{c}-\lambda_{s}\right) F}
$$

\subsection{Elasto-plastic solution}

From the elastic response of the unit cell it can be shown that significant yielding of the stone column may occur due to high stress ratio, but little yield in the clay. According to Balaam and Booker (1985) and Abdelkrim and Buhan (2007) a simplified calculation procedure may be adopted, which assumes that the soil remains elastic, the settlement evolution being governed by the progressive yield of the column as loading increases. Thus, elastic response of the soil will be assumed throughout the range of applied load.

Let us consider a thin horizontal slice of the "unit cell" at a selected depth $z$ before any load is applied on the ground surface. Let the effective vertical stress in the column at the depth $z$ be equal to $\sigma_{c s}=\gamma_{c} z$, where $\gamma_{c}$ is the effective unit weight of the column material. The initial lateral resistance can be estimated by $\sigma_{r c}=K_{i n i} \gamma_{s} z$, where $K_{i n i}$ is the initial lateral pressure coefficient at the soil/column interface after the installation of columns. The coefficient $K_{i n i}$ depends on the soil conditions, column spacing and the method of column installation. In very soft soils, for large column spacings and when replacement installation methods are used, the value of $K_{i n i}$ will be close to at rest value $k_{0}$. In opposite cases and especially when displacement installation methods are employed, $K_{i n i}$ can be significantly higher. In order to assure the elastic stress state for the column in its initial state (before loading), the value of $K_{i n i}$ should satisfy the condition $K_{i n i}>\gamma_{c} /\left(\gamma_{s} K_{p c}\right)$ (see Eq. 17).

For the perfectly elastic-plastic column material, satisfying the Mohr-Coulomb yield criterion, the yield condition for the stone column under applied load is given by the expression:

$$
\frac{\gamma_{c} z+\Delta \sigma_{z c}}{K_{i n i} \gamma_{s} z+\Delta \sigma_{r c}}=\frac{1+\sin \varphi_{c}}{1-\sin \varphi_{c}}=K_{p c}
$$

where $\Delta \sigma_{z c}$ and $\Delta \sigma_{r c}$ are elastic stress increments caused by the applied yield load $q^{y}$ (Eq. 7 and 12) and $\varphi_{c}$ is the peak friction angle of the column material. Equation 17 can be rearranged using Eq. 7 and Eq. 11 to obtain the yield load $q^{y}$ for the selected depth $Z$ :

$q^{y}=q^{y}(z)=C_{4} \gamma_{s} z$

with:

$C_{4}=\left(K_{p c} K_{i n i}-\mu\right) \frac{\left(\lambda_{c}+2 G_{c}\right) A_{r}+\left(\lambda_{s}+2 G_{s}\right)\left(1-A_{r}\right)-2 A_{r}\left(\lambda_{c}-\lambda_{s}\right) F}{2 G_{c}\left(1+F K_{p c}\right)+\lambda_{c}(1-2 F)\left(1-K_{p c}\right)}$

where $\mu$ represents the ratio of the effective column unit weight to the soil unit weight $\mu=\gamma_{c} / \gamma_{s}$. The elastic vertical deformation $\varepsilon_{z}^{y}$ under yield load $q^{y}$ (Eq. 7) now becomes: 
$\varepsilon_{z}^{y}=\varepsilon_{z}^{y}(z)=\frac{\left(K_{p c} K_{i n i}-1\right) \gamma_{s} z}{2 G_{c}\left(1+F K_{p c}\right)+\lambda_{c}(1-2 F)\left(1-K_{p c}\right)}$

If the surface load $q_{A}$ is greater than the yield load $q^{y}$ for the selected depth $z$, the column will yield and the yield criterion must also be satisfied for the column vertical and radial stress increments, $\Delta \sigma_{z c}^{p}$ and $\Delta \sigma_{r c}^{p}$, caused by the load difference

$q^{p}(z)=q_{A}-q^{y}(z)$ :

$\frac{\Delta \sigma_{z c}^{p}}{\Delta \sigma_{r c}^{p}}=\frac{1+\sin \varphi_{c}}{1-\sin \varphi_{c}}=K_{p c}$

where index $p$ denotes the share of stresses and strains caused by load difference $q^{p}$.

For the yielding Mohr-Coulomb elastic-plastic material with constant dilation angle $\psi$, the deformation ratio in triaxial conditions is defined by Rowe (1962):

$\frac{\Delta \varepsilon_{3}^{p}}{\Delta \varepsilon_{1}^{p}}=\frac{\Delta \varepsilon_{2}^{p}}{\Delta \varepsilon_{1}^{p}}=\frac{\varepsilon_{r}^{p}}{\varepsilon_{z}^{p}}=\frac{1+\sin \psi}{1-\sin \psi}=K_{\psi}$

Equation 22 provides a basis for the incremental stress-strain relationship, which was presented by Balaam and Booker (1985) in the form:

$\left\{\begin{array}{l}\Delta \sigma_{z c}^{p} \\ \Delta \sigma_{r c}^{p}\end{array}\right\}=D\left[\begin{array}{cc}K_{\psi} K_{p c} & -2 K_{p c} \\ K_{\psi} & -2\end{array}\right]\left\{\begin{array}{c}\varepsilon_{z}^{p} \\ \varepsilon_{r}^{p}\end{array}\right\}$

where $D$ is the material constant:

$D=\frac{E_{c}}{2+K_{\psi} K_{p c}-2 v_{c}\left(1+K_{p c}+K_{\psi}\right)}$

For the soil, which remains elastic, the stress-strain relationship presented by Poulos and Davis (1974) (Eq. 2) can be rearranged to obtain:

$\left\{\begin{array}{c}\Delta \sigma_{z s}^{p} \\ \Delta \sigma_{r s}^{p}\end{array}\right\}=E_{\text {oed }}\left[\begin{array}{cc}1 & C_{1} \\ k_{0} & C_{2}\end{array}\right]\left\{\begin{array}{l}\varepsilon_{z}^{p} \\ \varepsilon_{r}^{p}\end{array}\right\}$

Finally, the radial stress difference at the soil-column interface $\Delta \sigma_{r}^{p}=\Delta \sigma_{r c}^{p}-\Delta \sigma_{r s}^{p}$, which must be taken by the geosynthetic encasement, can be expressed as:

$F_{R}^{p}=\Delta \sigma_{r}^{p} r_{c}=\left(\Delta \sigma_{r c}^{p}-\Delta \sigma_{r s}^{p}\right) r_{c}=J \varepsilon_{r}^{p}$

By adopting the same kind of notation as in Section 2.1., the stress-strain relationships (Eq. 23, 25 and 26) and the equilibrium equation in the form:

$q^{p}=\Delta \sigma_{z c}^{p} A_{r}+\Delta \sigma_{z s}^{p}\left(1-A_{r}\right)$

are solved to obtain analytical closed-form solution for stresses and strains caused by the vertical load difference $q^{p}$ :

$\left\{\begin{array}{c}\varepsilon_{z}^{p} \\ \varepsilon_{r}^{p}\end{array}\right\}=\frac{1}{C_{5} E_{\text {oed }}}\left[\begin{array}{c}2 D+E_{\text {oed }}\left(C_{2}+T\right) \\ D K_{\psi}-k_{0} E_{\text {oed }}\end{array}\right]\left\{q^{p}\right\}$ 


$$
\begin{aligned}
& \left\{\begin{array}{l}
\Delta \sigma_{z c}^{p} \\
\Delta \sigma_{r c}^{p}
\end{array}\right\}=\frac{D}{C_{5}}\left[\begin{array}{c}
K_{p}\left[2 k_{0}+K_{\psi}\left(C_{2}+T\right)\right] \\
2 k_{0}+K_{\psi}\left(C_{2}+T\right)
\end{array}\right]\left\{q^{p}\right\} \\
& \left\{\begin{array}{c}
\Delta \sigma_{s c}^{p} \\
\Delta \sigma_{s c}^{p}
\end{array}\right\}=\frac{1}{C_{5}}\left[\begin{array}{c}
D\left(C_{1} K_{\psi}+2\right)+E_{o e d}\left(C_{3}+T\right) \\
D C_{2} K_{\psi}+2 D k_{0}+E_{\text {oed }} T k_{0}
\end{array}\right]\left\{q^{p}\right\}
\end{aligned}
$$

with:

$$
C_{5}=E_{\text {oed }}\left(1-A_{R}\right)\left(C_{3}+T\right)+D\left\{\left(1-A_{R}\right)\left(C_{1} K_{\psi}+2\right)+A_{R} K_{p}\left(K_{\psi}\left(C_{2}+T\right)+2 k_{0}\right)\right\}
$$

With the vertical strain of the untreated soil estimated as:

$$
\varepsilon_{z, 0}^{p}=\frac{q^{p}}{E_{\text {oed }}}
$$

the settlement reduction factor $\beta^{p}$ for the elasto-plastic response of the yielding column becomes:

$$
\beta^{p}=\frac{\varepsilon_{z}^{p}}{\varepsilon_{z, 0}^{p}}=\frac{2 D+E_{\text {oed }}\left(C_{2}+T\right)}{C_{5}}
$$

and similar to the elastic solution stress concentration factors $\eta_{c}^{p}$ and $\eta_{s}^{p}$ can be obtained as:

$$
\begin{aligned}
& \eta_{c}^{p}=\frac{\Delta \sigma_{z c}^{p}}{q^{p}}=\frac{D K_{p}\left\lfloor 2 k_{0}+K_{\psi}\left(C_{2}+T\right)\right\rfloor}{C_{5}} \\
& \eta_{s}^{p}=\frac{\Delta \sigma_{s p}^{p}}{q^{p}}=\frac{D\left(C_{1} K_{\psi}+2\right)+E_{\text {oed }}\left(C_{3}+T\right)}{C_{5}}
\end{aligned}
$$

\subsection{Complete elasto plastic response of the unit cell}

The complete elasto-plastic response of the unit cell under load is obtained as a combination of elastic and elasto-plastic solutions. Under distributed load $q_{A}$ the yield (bulging) of the column will start just below the ground surface within the zone with the least lateral resistance (Murugesan and Rajagopal, 2006; Gniel and Bouazza, 2009). For a given load the yield of the column will reach the final yield depth $z^{y}$ (Eq. 18):

$$
z^{y}=\frac{q_{A}}{C_{4} \gamma_{s}}
$$

Once the yield depth is determined, the vertical deformation $\varepsilon_{z}(z)$ can be calculated for two distinctive zones: for the depths $0<z<z^{y}$, where distributed load $q_{A}$ is greater than yield load $q^{y}(z)$ and for the depths $z \geq z^{y}$, where the column remains in the elastic state. Thus, the total vertical deformation $\varepsilon_{z}(z)$ is obtained as a combination of elastic and elasto-plastic solutions:

$$
\varepsilon_{z}(z)= \begin{cases}\varepsilon_{z}^{y}(z)+\varepsilon_{z}^{p}(z)=\frac{C_{4} \gamma_{s} z}{E_{\text {oed }}} \beta^{e l}+\frac{q_{A}-C_{4} \gamma_{s} z}{E_{\text {oed }}} \beta^{p} & \text { for } z<z^{y} \\ \varepsilon_{z}^{e l}=\frac{q_{A}}{E_{\text {oed }}} \beta^{e l} & \text { for } z \geq z^{y}\end{cases}
$$


Similarly, the vertical stress at the selected depth $\mathrm{z}$ in soil $(\alpha=s)$ and column $(\alpha=c)$ can be expressed in terms of stress concentration factors $\eta_{\alpha}^{e l}$ and $\eta_{\alpha}^{p}$ :

$\Delta \sigma_{z \alpha}(z)= \begin{cases}\eta_{\alpha}^{e l} q^{y}(z)+\eta_{\alpha}^{p}\left(q_{A}-q^{y}(z)\right) & \text { for } z<z^{y} \\ \eta_{\alpha}^{e l} q_{A} & \text { for } z \geq z^{y}\end{cases}$

and the circumferential force $F_{R}$ in the geosynthetic encasement as:

$$
F_{R}(z)= \begin{cases}J\left[F \frac{C_{4} \gamma_{s} z}{E_{\text {oed }}} \beta^{e l}+\frac{D K_{\psi}-k_{0} E_{\text {oed }}}{C_{5} E_{\text {oed }}}\left(q_{A}-C_{4} \gamma_{s} z\right)\right] & \text { for } z<z^{y} \\ J F \frac{q_{A}}{E_{\text {oed }}} \beta^{e l} & \text { for } z \geq z^{y}\end{cases}
$$

It is worth noting that the soil and column material properties can also be introduced as depth or stress dependent. In this case the final settlement must be obtained numerically, as opposed to the analytical solution for the constant depth independent material properties, where the final settlement of the treated ground is obtained with the integration of vertical strains over the length of column $H$ for three distinctive cases according to the calculated yield depth $z^{y}$ :

$$
u_{z}= \begin{cases}\int_{0}^{H} \varepsilon_{z}^{e l} d z=\frac{q_{A} H}{E_{\text {oed }}} \beta^{e l} & \text { for } \quad z^{y} \leq 0 \\ \int_{0}^{z^{y}}\left(\varepsilon_{z}^{y}(z)+\varepsilon_{z}^{p}(z)\right) d z+\int_{z^{y}}^{H} \varepsilon_{z}^{e l} d z & \text { for } \quad 0<z^{y}<H \\ \int_{0}^{H}\left(\varepsilon_{z}^{y}(z)+\varepsilon_{z}^{p}(z)\right) d z & \text { for } \quad z^{y} \geq H\end{cases}
$$

If the settlement of the treated ground $u_{z}$ is divided by the total settlement of the homogeneous untreated ground, which can be for sufficiently large load area estimated as:

$$
u_{z, 0}=\frac{q_{A} H}{E_{\text {oed }}}
$$

then, after the integration of Eq. 40, the final settlement reduction factor $\beta$ becomes:

$$
\beta= \begin{cases}\beta^{e l} & \text { for } z^{y} \leq 0 \\ \beta^{e l}\left(1-\frac{q_{A}}{2 C_{4} H \gamma_{s}}\right)+\beta^{p}\left(\frac{q_{A}}{2 C_{4} H \gamma_{s}}\right) & \text { for } 0<z^{y}<H \\ \beta^{e l}\left(\frac{C_{4} H \gamma_{s}}{2 q_{A}}\right)+\beta^{p}\left(1-\frac{C_{4} H \gamma_{s}}{2 q_{A}}\right) & \text { for } z^{y} \geq H\end{cases}
$$

As the settlement reduction factors $\beta^{e l}$ (Eq.13) and $\beta^{p}$ (Eq. 33) and $C_{4}$ (Eq. 19) are constant for a given set of material, geometrical and initial stress data, the final settlement reduction factor $\beta$ for a yielding column (Eq. 42) results in a linear 
combination of elastic and plastic solutions governed by the dimensionless load ratio $q_{A} /\left(H \gamma_{s}\right)$. Similar effect of dimensionless load ratio $q_{A} /\left(H \gamma_{s}\right)$ on settlement reduction was presented for non-encased columns (Balaam and Booker, 1985) and is further discussed in Chapter 4.

Similarly, the ultimate stress concentration factor for soil $(\alpha=s)$ and column $(\alpha=c)$ can be expressed as:

$\eta_{\alpha}(z)=\frac{\Delta \sigma_{z \alpha}(z)}{q_{A}}=\left\{\begin{array}{cl}\eta_{\alpha}^{e l}\left(\frac{C_{4} \gamma_{s} z}{q_{A}}\right)+\eta_{\alpha}^{p}\left(1-\frac{C_{4} \gamma_{s} z}{q_{A}}\right) & \text { for } z<z^{y} \\ \eta_{\alpha}^{e l} & \text { for } z \geq z^{y}\end{array}\right.$

From Eq. 43 it is obvious that for the yielding column the stress concentration factors for the soil $\eta_{s}$ and the column $\eta_{c}$ are not constant over the column depth. Thus, the settlement reduction factor $\beta$ can not be easily expressed in terms of stress concentration factors.

For the homogenous soil and column constant $C_{4}$, settlement reduction factors $\left(\beta^{e l}\right.$, $\left.\beta^{p}\right)$ and stress concentration factors $\left(\eta_{\alpha}^{e l}, \eta_{\alpha}^{p}\right)$ are load/depth independent and can be calculated easily for a given set of material parameters and column distribution ("? see Electronic Annex 1 in the online version of this article").

Another important feature of the method is that it is valid also for ordinary non-encased stone columns, if geosynthetic encasement is neglected. Numerically it is done simply by adjusting the encasement stiffness to zero value $(J=0)$.

\section{Model validity}

To test the validity of the proposed method, elasto-plastic finite element analyses were performed by using commercial Plaxis 2D finite element program (Brinkgrave, 2002). Axi-symmetric model was used for the circular "unit cell" and 15-node triangular elements were selected to model the soil and column material. Along the axis and outer border of the unit cell radial deformations were restricted but settlements were allowed. The base and the foundation were assumed as perfectly rough, as earlier work presented by Balaam and Booker, 1981, showed that even for a very shallow layer $\left(H / d_{c}=1\right)$ the surface vertical displacement is almost insensitive to the imposed boundary condition at the top and the bottom of the model. A raft with high flexural stiffness was modelled at the surface to simulate the stiffness of the imposed uniform load and to match the assumptions of the analytical method. Furthermore, the drained conditions were used and the creep of geosynthetic was not considered in order to stay within the assumptions of the analytical method.

Special membrane elements with elastic axial stiffness $E A$ but with no bending stiffness were used to model the geosynthetic encasement. These membrane elements can only sustain tensile forces but no compression and are capable to model the encasement. No 
special shear (interface) elements were used along column-encasement and soilencasement interfaces.

More exact elasto-plastic numerical analyses were used intentionally, not to impose any assumptions about the final stress state in the soil or in the column and to verify some assumptions of the presented method (e.g. soil remains in elastic state under loading). Consequently, the soil and the column material were both treated as perfectly elastoplastic materials according to the Mohr-Coulomb yield criterion with non-associated flow rule.

The analyses were made for two different spacings $d_{e} / d_{c}=2$ and 5 with respective replacement ratios $A_{R}=25 \%$ and $4 \%$. For the economic and technical feasibility, such replacement ratios are usually considered as limit values.

The column length to diameter ratio $H / d_{c}=10$, the modulus ratio $E_{c} / E_{s}=30$, the effective unit weight ratio $\mu=\gamma_{c} / \gamma_{s}=1.5$, the column friction angle $\varphi_{c}=40^{\circ}$ and the soil friction angle $\varphi_{s}=25^{\circ}$ were adopted for the analyses. Poisson's ratios $\nu_{c}=v_{s}=0.3$ were assumed for the soil and column material. The soil was treated as non-dilatant $\left(\psi_{s}=0\right)$ and the column as non-dilatant $\left(\psi_{c}=0\right)$ or as dilatant material $\left(\psi_{c}=15^{\circ}\right)$. Dilation angle $\psi_{c}=0$ was assumed as a conservative assumption, which gives the largest settlements (Fig. 12) and also means the maximum deviation from the elastic response. Alternatively, $\psi_{c}=15^{\circ}$ was assumed to validate the method for the effects of dilation. The initial stresses were generated according to the $K_{0}$ procedure for the assumed value of soil stress coefficient $K_{i n i}=0.8$.

High load level was selected deliberately to test the ability of the method to give reasonable predictions of settlements, stresses and encasement hoop forces for large loads/deformations. Thus, the maximum applied load in the analyses $q_{\mathrm{A}}=0.20 E_{\text {oed }}$ was selected, causing the vertical deformation of the untreated ground in the order of $20 \%$. The maximum dimensionless load factor considered in the analysis was $q_{A} /\left(H \gamma_{s}\right)=2.0$

For the elastic geosynthetic encasement a dimensionless stiffness $T$, in which the encasement stiffness $J$ is normalized by oedometer modulus $E_{\text {oed }}$ of soil and column radius $r_{c}$ (Eq. 9), was used in the analyses. Non-encased stone columns with $T=0$ and encased stone columns with four different dimensionless stiffnesses $T=2.5,5,10$ and 15 , were analyzed, covering a broad range of suitable geosynthetic products and soil conditions.

The above parameters were considered as a combination of data which would thoroughly test the validity of the assumptions, regularity and accuracy of the presented method.

Fig. 2. 
Figures 2 and 3 show the comparison between the results of finite element method (FEM) and the presented analytical method for the selected parameters and non-dilatant column material $\left(\psi_{c}=0\right)$. The normalized value of the calculated settlement $u_{z} E_{\text {oed }} /\left(H^{2} \gamma_{s}\right)$ and average vertical strain $\varepsilon_{z}$ is depicted in relation to the normalized load ratio $q_{A} /\left(H \gamma_{s}\right)$, as it is obvious from Eq. 42 that for a given set of geometrical and material data the settlement reduction factor $\beta$ depends only on the load level $q_{A} /\left(H \gamma_{s}\right)$. Similar comparison of results is shown in Fig. 4 for the dilatant column material $\left(\psi_{c}=15^{\circ}\right)$ and two dimensionless stiffnesses $T=2.5$ and 10 . The data for the untreated soil were calculated according to one-dimensional theory and checked with the finite element analysis.

Fig. 3.

The maximum difference between the settlements according to both methods was found to be in the order of $2.5 \%$ of the final settlement of untreated ground. For high encasement stiffness $(T>5)$ the difference between calculated settlements was even lower, usually well below $1.0 \%$. When dilation of the column was taken into account $\left(\psi_{c}=15^{\circ}\right)$, the results from both methods almost coincide.

\section{Fig. 4.}

The comparison of the calculated column radial deformations along the soil/column interface for column spacing ratio $d_{e} / d_{c}=5$ and for various load levels is shown in Figure 5. The calculated radial deformations, which are directly related to the encasement hoop forces $\left(F_{R}=J \varepsilon_{r}\right)$, are in close agreement with the average values of radial deformations calculated with finite element analyses, although some variation of the radial deformations can be observed as a consequence of column yield and strain localization in the finite element analyses.

\section{Fig. 5.}

Although in the proposed analytical solution the soil is considered as an elastic material and the shear stresses along the column-soil interface are neglected, the calculated settlements are in very good agreement with the finite element results throughout the applied load. As almost no yielding was found in the soil, the results are in line with the findings presented by Balaam and Booker (1985), Abdelkrim and Buhan (2007) and Murugesan and Rajagopal (2006), i.e. that a simplified calculation procedure may be adopted, which assumes that the soil remains elastic, the settlement evolution being governed by the progressive yield of the column as loading increases.

The results clearly indicate the validity of the assumptions and ability of the method to give good predictions of settlements, stresses and encasement forces for the encased and non-encased stone columns. Thus, the method will be used in a parametric study to investigate the influence of various parameters, such as soil/column parameters, 
replacement ratio, load level and stiffness of geosynthetic encasement, on the behaviour of the improved ground.

\section{Parametric study}

In addition to the soil and column material properties, such as modulus ratio $E_{c} / E_{s}$, friction angle of the column material $\varphi_{c}$, dilation angle $\psi$ and Poisson's ratios $v_{c}$ and $v_{s}$, the most important parameters affecting the behaviour of the stabilized ground are column spacing ratio $d_{e} / d_{c}$, encasement stiffness $J$, dimensionless load factor $q_{A} /\left(H \gamma_{s}\right)$ and initial lateral earth pressure coefficient $K_{i n i}$.

The same basic material and geometrical data as for the validation analyses were adopted for the parametric study. Individual data were varied to show the effect of the most important input data on the settlement reduction.

\section{Fig. 6.}

The effects of column spacing, load factor and geosynthetic stiffness on settlement reduction factor $\beta$ are shown in Figures 6,7 and 8 . The column spacing ratio $d_{e} / d_{c}$ and the dimensionless encasement stiffness $T$ have a dominating effect on the settlement reduction. Increasing the column diameter and decreasing the spacing between them, thereby increasing the replacement ratio $A_{R}$, leads to significant reduction of settlements as compared to the untreated ground.

Fig. 7.

Fig. 8.

The beneficial effect of the encasement on the settlement reduction is clearly evident. Increased encasement stiffness reduces radial deformations and provides additional lateral support for the column, which consequently takes more load and increases the stiffness of the stabilized ground. However, it should be noted that the beneficial effect of the encasement stiffness decreases with the increasing column radius $r_{c}$ and with the increasing stiffness of the soil. Therefore, the dimensionless stiffness $T$ is more appropriate for the proper selection of the geosynthetic encasement than its tensile modulus by itself.

The effect of dimensionless-load factor $q_{A} /\left(H \gamma_{s}\right)$ is also important, as it affects the unit cell response and especially the column yield. The settlement reduction factor $\beta$ (Eq. 42) is a linear combination of elastic and elasto-plastic solutions $\beta^{e l}$ and $\beta^{p}$ governed by the dimensionless load factor $q_{A} /\left(H \gamma_{s}\right)$. If the column is long and the applied load is small compared to the effective stresses at the column bottom, then most of the column will stay in the elastic state, thus having a significant effect on the settlement reduction with the final settlement reduction factor $\beta \approx \beta^{e l}$. As the load 
increases, the column yields and plastic deformations dominate over the elastic ones. Comparisons of the results given in Figures 6,7 and 8 shows that for higher loads the settlement reduction factor $\beta$ quickly approaches to $\beta^{p}$. Thus, for the load factors $q_{A} /\left(H \gamma_{s}^{\prime}\right)>1$ only the elasto-plastic part of the solution can be used as a conservative estimate of final settlements.

Another interesting feature of the method is its ability to predict the behaviour of the stabilized ground irrespective of the spacing ratio $d_{e} / d_{c}$. For the theoretical $100 \%$ replacement of the soil $\left(d_{e} / d_{c}=1.0\right)$ the calculated settlement reduction factor $\beta$ becomes equal to soil modulus ratio $E_{s} / E_{c}$, while for zero replacement it becomes equal to unity irrespective of the encasement stiffness. This is clearly shown in Figures 6, 7 and 8 , where for $E_{c} / E_{s}=30$ the calculated settlement reduction factor $\beta$ approaches to the value of $1 / 30$, as the column spacing ratio decreases to unity. As expected, no column yield occurs under such theoretical condition and the calculated settlement is the same as obtained from the one-dimensional theory for thirty times stiffer material.

In Figure 9 the settlement reduction factor $\beta$ is plotted against the dimensionless load factor $q_{A} /\left(H \gamma_{s}\right)$ for modulus ratios $E_{c} / E_{s}=20,30$ and 40 for encasement stiffness $\mathrm{T}$ $=0,2.5$ and 10. The loss of stiffness with increasing load is most evident for the nonencased columns with very high modulus ratio. With high modulus ratio the column takes greater proportion of the load, as long as it remains in the elastic state. Upon yielding, the deformation process is not longer controlled by the stiffness of the column and as the load increases the initial influence of the modulus ratio on the settlement reduction becomes negligible. The loss of stiffness is therefore most evident for nonencased columns, where relatively low load is sufficient to cause the column to yield. For relatively weak encasements $(T=2.5)$ similar reduction of stiffness with the increasing load can be observed, although not so clearly evident. As the encasement becomes stiffer, the column yield resistance increases due to the additional lateral support and the loss of stiffness with increasing load becomes less evident.

Fig. 9.

In Figure 10 the effect of column friction angles $\left(\varphi_{c}=35^{\circ}, 40^{\circ}\right.$ and $\left.45^{\circ}\right)$ and encasement stiffness ( $T=0,2.5$ and 10) on settlement reduction is shown. It is obvious that the loss of stiffness with the increasing load is less severe for the column material having a higher friction angle and stiffer encasement. The beneficial effect of higher friction angle is most obvious for non-encased stone columns and tends to decrease with increasing encasement stiffness.

Fig. 10.

Fig. 11.

As the confining generated in the encased columns is generally higher than in nonencased columns (Murugesan and Rajagopal, 2006), the effect of initial lateral stresses 
in the soil/column interface was also considered in the parametric study. Initial radial stresses in the "unit cell" depend on the stone-column installation technique and soil properties and are often assumed on the basis of engineering experience. To show the effect of lateral stress coefficient $K_{i n i}$ on the settlement reduction factor $\beta$, parametric calculations were made by adopting $K_{i n i}=0.7,0.8$ and 0.9 . The results are shown in Figure 11. The positive effect of initial radial stresses on the settlement reduction is clearly indicated for non-encased columns under relatively small load $\left(q_{A} /\left(H \gamma_{s}\right)<1.0\right)$. For encased columns the beneficial effect of initial radial stresses decreases with increasing encasement stiffness and load. This occurs because the radial stresses at soil/column interface generated by high loads are far higher than the initial radial stresses, which are therefore not very important for the final column stress state and have little impact on the behaviour of the stabilized ground. With stiffer encasement the ratio between generated and initial stresses in the column increases even more and the beneficial effect of the initial stresses on the performance becomes almost negligible, as shown in Fig. 11.

Fig. 12.

Another positive effect of the column encasement is that it allows better densification of the column material and thus higher peak shear strength and higher dilation angle of the column material. The effect of dilation angle $\psi$ is shown in Fig. 12. The dilatancy increases stiffness of stabilized ground because of the volume increase of the column material during yield. The effect of dilatancy is, as expected, more pronounced at higher loads when the column yields over the entire length and decreases as the encasement becomes stiffer. However, it should be noted that post peak behaviour of the column material is not taken into account and for the deformations far beyond the deformations at peak shear strength it is unrealistic to expect that the material will retain its ability to increase volume. Thus, the selection of the dilation angle should always be made in accordance with the actual behaviour of the column material within the range of expected deformations. When in doubt, the assumption that stone column material is non-dilatant $\left(\psi=0^{\circ}\right)$ will generally lead to conservative predictions of settlements.

The results presented in Figures 7 to 12 show that for given properties of soil and column material the most significant reduction of settlements occurs when the columns are closely spaced, the tensile modulus of the encasement is high and the load level is low.

\section{Design charts}

When designing stone columns in engineering practice, one of the main objectives is to reduce settlements to the acceptable level. For given material data and load the reduction of settlements can by enhanced in two ways: by reducing the column spacing $d_{e} / d_{c}$ and therefore increasing the replacement ratio $A_{R}$ or by increasing the encasement stiffness $J$. The proposed method allows for the generation of the design charts which enables quick preliminary selection of appropriate column spacing or encasement stiffness for the desired settlement reduction. 
For the basic set of material data $\left(E_{c} / E_{s}=30, \varphi_{c}=40^{\circ}, \psi=0^{\circ}, \mu=1.5, K_{i n i}=0.8\right)$ such a design chart is shown in Figure 13. Several sets of lines are depicted for different settlement reduction factors $\beta=0.2-0.7$ and load levels $q_{A} /\left(H \gamma_{s}\right)=0.5$ and 2.0, to show the interdependence of column spacing ratio $d_{e} / d_{c}$ and dimensionless encasement stiffness $T$ on the reduction of settlements. As shown in Figure 13, the need for stiffer encasement rapidly increases for tightly spaced columns and when low settlement reduction factor $\beta$ is desired. Obviously, by increasing the spacing ratio $d_{e} / d_{c}$ the loss of overall stiffness is more severe for tightly spaced columns and therefore very stiff encasement is needed to retain the same settlement reduction. The effect of the load ratio $q_{A} /\left(H \gamma_{s}\right)$ on the settlement reduction and thus on column spacing and encasement stiffness is also clearly indicated. As the load increases, the demand for stiffer encasement is more pronounced for tightly spaced columns and when high settlement reduction is desired.

Fig. 13.

\section{Comparison to other methods}

The results from the proposed method were compared with the analytical method proposed by Reithel and Kempfert (2000), which is probably the most popular and accepted method in engineering practice. The analytical method is based on the same unit cell concept, with the soil and geosynthetic encasement considered similarly as linear-elastic materials.

In the analysis presented by Reithel and Kempfert (2000) the column material is considered as rigid-plastic material, with infinite modulus of elasticity, yield limit at the active state and plastic deformation at constant volume (zero dilatancy), as opposed to the presented method, where the column is considered as a dilatant elasto-plastic material. The second main difference is the adoption of second-order strain theory as opposed to the first-order strain theory adopted in the presented method.

Fig. 14.

Although the number of input parameters for both methods is not the same, the comparison of the predicted settlements can easily be made for the basic material and geometrical data previously adopted for the validation analyses $\left(E_{c} / E_{s}=30, \varphi_{c}=40^{\circ}\right.$, $\left.\psi=0^{\circ}, \mu=1.5, v_{s}=v_{c}=0.3, k_{0}=0.43, K_{\text {ini }}=0.8\right)$. Another set of calculations was made according to the proposed method by adopting very high modulus for the column material $\left(E_{c} / E_{s}=3000\right)$ and Poisson's ratio $v_{c} \approx 0.5$ to compare the results for the case of almost incompressible column with those obtained by Reithel and Kempfert's method (2000).

Fig. 15. 
The predicted settlement reductions are plotted for different encasement stiffnesses ( $T=0,2.5$ and 15) and varying spacings $d_{e} / d_{c}$ for two load levels $q_{A} /\left(H \gamma_{s}\right)=0.5$ and 2.0 in Figures 14 and 15, respectively.

For almost incompressible column material with high modulus ratio $\left(E_{c} / E_{s}=3000\right)$ the results from both methods almost coincide. For low load levels $\left(q_{A} /\left(H \gamma_{s}\right)=0.5\right)$ the results coincide perfectly, while for higher load levels $q_{A} /\left(H \gamma_{s}\right)=2.0$ small differences appear, which can be attributed to the different orders of strain theory applied in both methods.

However, results from both methods can differ significantly when the compressibility of the column material is taken into account. As would be expected, the assumption of incompressibility of the column material results in the overestimation of settlement reduction, particularly for high encasement stiffness. For the non-encased columns the differences in results from both methods are small, but they tend to increase as the encasement stiffness increases and as the deformation modulus of the column $E_{c}$ decreases. This occurs because the higher the encasement stiffness, the higher the portion of the vertical load carried by the column before it yields and thus the higher the accumulated elastic column deformations caused by stress concentration. In the nonencased columns the stress level at yield is too low to generate any significant volume change. Thus, similar results are obtained from both methods. On the other hand, for the encased columns additional lateral support is provided and the column is able to carry more vertical load. Although it yields at the same ratio between vertical and radial stresses, the overall stress level at yield is much higher and so are the accumulated elastic deformations during the load increase. Thus, the incorporation of compressibility and dilatancy of column material into the presented closed-form solution represents important improvement for the prediction of load settlement response of the nonencased and encased stone columns reinforced ground.

\section{Conclusions}

A simple and effective analytical closed-form solution for the analysis of non-encased and encased stone column reinforced ground is presented. The regularly spaced endbearing stone columns and the surrounding soil are modelled as a unit cell, consisting of elastic soil, elasto-plastic Mohr-Coulomb column material and elastic geosynthetic encasement. The dilation of the column material according to the Rowe stress-dilatancy theory is directly incorporated into the method.

The comparisons with finite element analyses have shown the ability of the proposed method to yield good predictions of the behaviour of encased and non-encased stone columns reinforced ground. Based on the method characteristics and comparative finite element analyses the following conclusions are made:

- The comparative study shows that the model assumptions are valid.

- The proposed method is able to give predictions of settlements, stresses in soil and column and forces in encasement in a very close agreement with the elasto-plastic finite 
element analyses. For relatively stiff encasement $(T>5)$ the calculated settlements almost coincide with the finite element results.

- For homogenous soil conditions a simple closed-form solution is obtained for the prediction of the effects of stone-columns on settlement reduction, stresses in the soil and column and geosynthetic forces, which can be easily used in engineering practice. - The method is suitable for non-encased and encased stone columns.

- The method is capable to predict the behaviour of uniformly loaded stabilized ground irrespective of the spacing ratio $d_{e} / d_{c}$. For the theoretical $0 \%$ and $100 \%$ soil

replacement the method generates results consistent with the one-dimensional theory.

- In general, the method can also be used for non-homogeneous soil conditions and for partially encased stone columns. For such conditions the calculation must be done in the incremental form or numerically.

Based on parametric study where the influences of the material properties, column spacing and encasement stiffness are taken into account, further conclusions are made:

- Most important parameters affecting the behaviour of stabilized ground are column spacing ratio $d_{e} / d_{c}$, dimensionless encasement stiffness $T=J /\left(E_{\text {oed }} r_{c}\right)$, peak friction angle of the column material $\varphi_{c}$, dilation angle of the column material $\psi$, modulus ratio $E_{c} / E_{s}$ and load level $q_{A} /\left(H \gamma_{s}\right)$.

- The selection of encasement stiffness $J$ should be made in relation to the column diameter, soil stiffness and column spacing.

- Dilation of the column material has a beneficial effect on the settlement reduction and should be considered in the design. For the conservative predictions the dilation of the column material can be neglected by adopting $\psi=0^{\circ}$.

- For high load levels $\left(q_{A} /\left(H \gamma_{s}\right)>2\right)$ the elastic part of the solution becomes negligible and only elastic-plastic part of the solution can be used conservatively to simplify the analytical method even further.

\section{Appendix. Notation}

The following symbols are used in this paper:

$\begin{array}{ll}A_{c}, A_{e} & =\text { area of column and unit cell (influence area); } \\ A_{r} & =\text { replacement ratio; } \\ C_{1}, C_{2}, C_{3}, C_{4}, C_{5} & =\text { material/geometrical constants; } \\ D & =\text { material constant; } \\ d_{c} & =\text { diameter of stone-column; } \\ d_{e} & =\text { diameter of influence area; } \\ E_{\text {oed }} & =\text { oedometer modulus of soil; } \\ E_{\alpha} & =\text { elastic modulus of soil }(\alpha=s) \text { or column }(\alpha=c) ; \\ F & =\text { material/geometrical constant; } \\ G_{\alpha} & =\text { shear modulus of soil }(\alpha=s) \text { or column }(\alpha=c) ; \\ J & =\text { geosynthetic encasement stiffness; } \\ H & =\text { column height; } \\ k_{0} & =\text { coefficient of earth pressure at rest; }\end{array}$


$K_{\text {ini }}$

columns;

$$
\begin{aligned}
& K_{p c} \quad=\text { passive earth pressure coefficient; } \\
& K_{\psi} \quad=\text { dilation constant; } \\
& q_{\mathrm{A}} \quad=\text { applied vertical distributed load; } \\
& q^{p} \quad=\text { load difference; } \\
& q^{y} \quad=\text { yield load; } \\
& r_{c} \quad=\text { radius of stone-column; } \\
& r_{e} \quad=\text { radius of influence area; } \\
& S \quad=\text { stone-column spacing; } \\
& F_{R} \quad=\text { encasement hoop force; } \\
& T=\text { dimensionless encasement stiffness; } \\
& u_{r}, u_{z} \quad=\text { radial and vertical displacement; } \\
& z \quad=\text { depth; } \\
& \beta, \beta^{e l}, \beta^{p} \quad=\text { settlement reduction factors; } \\
& \varepsilon_{r}, \varepsilon_{z} \quad=\text { radial and vertical strain; } \\
& \varepsilon_{r}^{e l}, \varepsilon_{z}^{e l} \quad=\text { elastic radial and vertical strain; } \\
& \varepsilon_{r}^{p}, \varepsilon_{z}^{p} \quad=\text { plastic radial and vertical strain; } \\
& \gamma_{\alpha} \quad=\text { effective unit weight of soil }(\alpha=s) \text { or column }(\alpha=c) \text {; } \\
& \eta_{\alpha}^{e l}, \eta_{\alpha}^{p} \quad=\text { stress concentration factors of soil }(\alpha=s) \text { or column }(\alpha=c) \text {; } \\
& \varphi_{c} \quad=\text { peak friction angle of column material; } \\
& v_{\alpha} \quad=\text { Poisson's ratio of soil }(\alpha=s) \text { or column }(\alpha=c) \text {; } \\
& \lambda_{\alpha} \quad=\text { Lame's parameter of soil }(\alpha=s) \text { or column }(\alpha=c) \text {; } \\
& \mu \quad=\text { effective unit weight ratio; } \\
& \sigma_{r \alpha}, \sigma_{z \alpha} \quad=\text { radial and vertical stress in soil }(\alpha=s) \text { or column }(\alpha=c) \text {; } \\
& \Delta \sigma_{r \alpha}, \Delta \sigma_{z \alpha} \quad=\text { radial and vertical stress increase in soil }(\alpha=s) \text { or column } \\
& (\alpha=c) \text {; } \\
& \Delta \sigma_{r \alpha}^{p}, \Delta \sigma_{z \alpha}^{p} \quad=\text { plastic radial and vertical stress increase in soil }(\alpha=s) \text { or } \\
& \text { column }(\alpha=c) \text {; } \\
& \begin{array}{ll}
\Delta \sigma_{r} & =\text { radial stress difference; } \\
\psi & =\text { dilation angle. }
\end{array}
\end{aligned}
$$

\section{References}

1. Abdelkrim, M., De Buhan, P., 2007. An elastoplastic homogenization procedure for predicting the settlement of a foundation on a soil reinforced by columns. European Journal of Mechanics and Solids 26, 736-757.

2. Aboshi, H., Ichimoto, E., Enoki, M., Harada, K., 1979. The compozer - a method to improve characteristics of soft clay by inclusion of large diameter sand columns. In: 
Proceedings of International Conference on Soil Reinforcement: Reinforced Earth and Other Techniques, E.N.P.C., 1, Paris, pp. 211-216.

3. Araujo, G.L.S., Palmeira, E.M., Cunha, R.P., 2009. Behaviour of geosyntheticencased granular columns in porous collapsible soil. Geosynthetics International 16 (6), 433-451.

4. Balaam, N.P., Booker, J.R., 1981. Analysis of rigid rafts supported by granular piles. International Journal for Numerical and Analytical Methods in Geomechanics 5, 379403.

5. Balaam, N.P., Booker, J.R., 1985. Effects of stone columns yield on settlement of rigid foundations in stabilized clay. International Journal for Numerical and Analytical Methods in Geomechanics 9, 331-351.

6. Barksdale, R.D., Bachus R.C., 1983. Design and construction of stone columns. Report FHWA/RD-83/026, National Information Service, Springfield, Virginia.

7. Brinkgrave, R.B.J, Plaxis 2D - Version 8. A.A. Balkema, Netherlands.

8. Gniel, J., Bouazza, A., 2009. Improvement of soft soils using geogrid encased stone columns. Geotextiles and Geomembranes 27, 167-175.

9. Gniel, J., Bouazza, A., 2010. Construction of geogrid encased stone columns: A new proposal based on laboratory testing. Geotextiles and Geomembranes 28, 108-118.

10. Malarvizhi, S.N., Ilamparuthi, K., 2007. Comparative behaviour of encased stone column and conventional stone column, Soils and Foundations 47 (5), 873-885.

11. Murugesan, M., Rajagopal, K., 2006. Geosynthetic-encased stone columns:

Numerical evaluation. Geotextiles and Geomembranes 24, 349-358.

12. Murugesan, M., Rajagopal, K., 2007. Model test on geosynthetic-encased stone columns . Geosynthetics International 14 (6), 346.

13. Murugesan, M., Rajagopal, K., 2010. Studies on the behaviour of single and group of geosynthetic encased stone columns. Journal of Geotechnical and Geoenvironmental engineering 136 (1), 129-139.

14. Poulos, H.G., Davis, E.H., 1974. Elastic Solutions for Soil and Rock Mechanics. Wiley, New York.

15. Priebe, H., 1976. Abschatzung des Setzungverhaltens eines durch Stoppverdichtung verbesserten Baugrundes. Die Bautechnik 5, 160-162.

16. Pulko, B., Majes, B., 2005. Simple and accurate prediction of settlements of stone column reinforced soil. In: Proceedings of 16th International Conference on soil Mechanics and Foundation Engineering, Osaka, Japan, Vol. 3, pp. 1401-1404. 17. Pulko, B., Majes, B., 2006. Analytical method for the analysis of stone-columns according to the Rowe dilatancy theory. Acta Geotechnica Slovenica, 3 (1), 37-45. 18. Raithel, M., Kempfert,. H.G., 2000. Calculation models for dam foundation with geotextile coated sand columns. In: Proceeding of the International Conference on Geotechnical \& Geological Engineering, Geo-Eng -2000, Melbourne.

19. Raithel, M., Kempfert,. H.G., Kirchner, A., 2002. Geotextile-encased columns (GEC) for foundation of a dike on very soft soils. In: Proceedings of the Seventh International Conference on Geosynthetics, Nice, France, pp. 1025-1028.

20. Rowe, P.W., (1962). The stress-dilatancy relation for static equilibrium of an assembly of particles in contact. In: Proceedings of Royal Society, 269A, 500-527. 21. Sivakumar, V., McKelvey, J., Graham, J., Hughes, D., 2004. Triaxial test on model sand columns in clay. Canadian Geotechnical journal 41, 299-312. 
22. Van Impe, W.F., De Beer, E., 1983. Improvement of settlement behaviour of soft layers by means of stone columns. In: Proceedings of $8^{\text {th }}$ European Conference on Soil Mechanics and Foundation Engineering, Helsinki, Vol. 1, 309-312.

23. Van Impe, W.F., Madhav, M.R., 1992. Analysis and settlement of dilating stone column reinforced soil. Österrichische Ingenieur and Architekten Zeitschrift (ÖIAZ), 137(3), 114-121.

24. Yoo, C., Kim, S.B., (2007). Numerical modelling of geosynthetic-encased stone column-reinforced ground. Geosynthetics International 16 (3), 116-126.

\section{Figure captions:}

Fig. 1: Basic features of the model based on regular patterns of stone-columns.

Fig. 2. Comparison between finite element analysis and analytical method $\left(d_{e} / d_{c}=2.0, \psi_{c}=0\right)$.

Fig. 3. Comparison between finite element analysis and analytical method $\left(d_{e} / d_{c}=5.0, \psi_{c}=0\right)$.

Fig. 4. Comparison between finite element analysis and analytical method $\left(\psi_{c}=15^{\circ}\right)$

Fig. 5. Comparison of radial deformations $\left(d_{e} / d_{c}=5.0, T=2.5, \psi_{c}=0\right)$.

Fig. 6. Effect of load factor on settlement reduction for non-encased columns $(J=T=0)$.

Fig. 7. Effect of load factor on settlement reduction factor $\beta$ for weak encasement $(T=2.5)$.

Fig. 8. Effect of load factor on settlement reduction factor $\beta$ for stiff encasement $(T=10)$.

Fig. 9. Effect of modulus ratio $E_{c} / E_{s}$ on settlement reduction $\left(d_{e} / d_{c}=3, T=0,2.5\right.$ and 10).

Fig. 10. Effect of friction angle $\varphi_{c}$ on settlement reduction $\left(d_{e} / d_{c}=3, T=0,2.5\right.$ and $10)$.

Fig. 11. Effect of $K_{i n i}$ on settlement reduction $\left(d_{e} / d_{c}=3, T=0,2.5\right.$ and 10).

Fig. 12. Effect of dilatancy on settlement reduction factor $\beta\left(d_{e} / d_{c}=3, T=0,2.5\right.$ and 10).

Fig. 13. Design chart for the settlement reduction.

Fig. 14. Comparison of authors' method with that of Reithel and Kempfert (2000) $q_{A} /\left(H \gamma_{s}\right)=0.5$.

Fig. 15. Comparison of authors' method with that of Reithel and Kempfert (2000) $q_{A} /\left(H \gamma_{s}\right)=2.0$ 


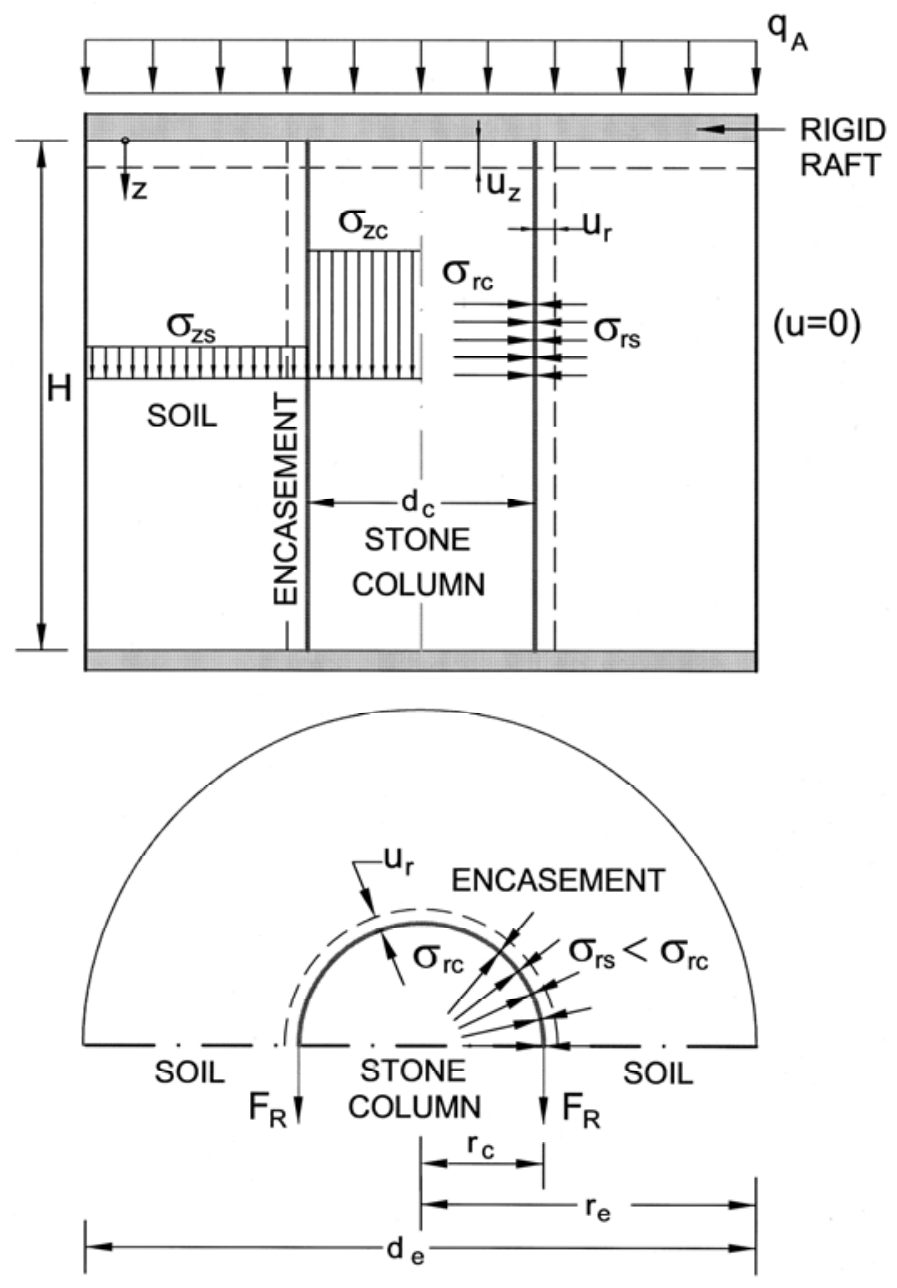

Fig. 1. 


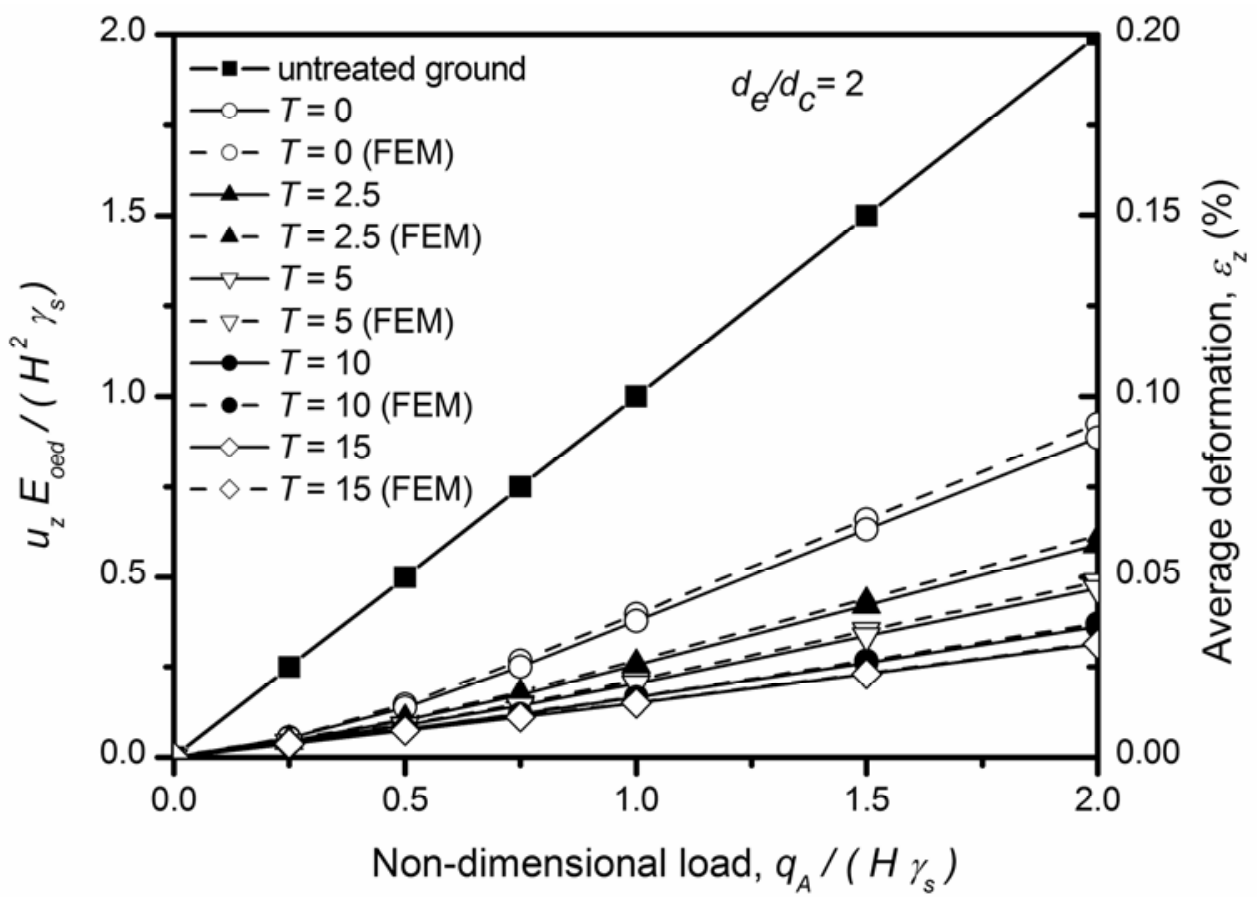

Fig. 2. 


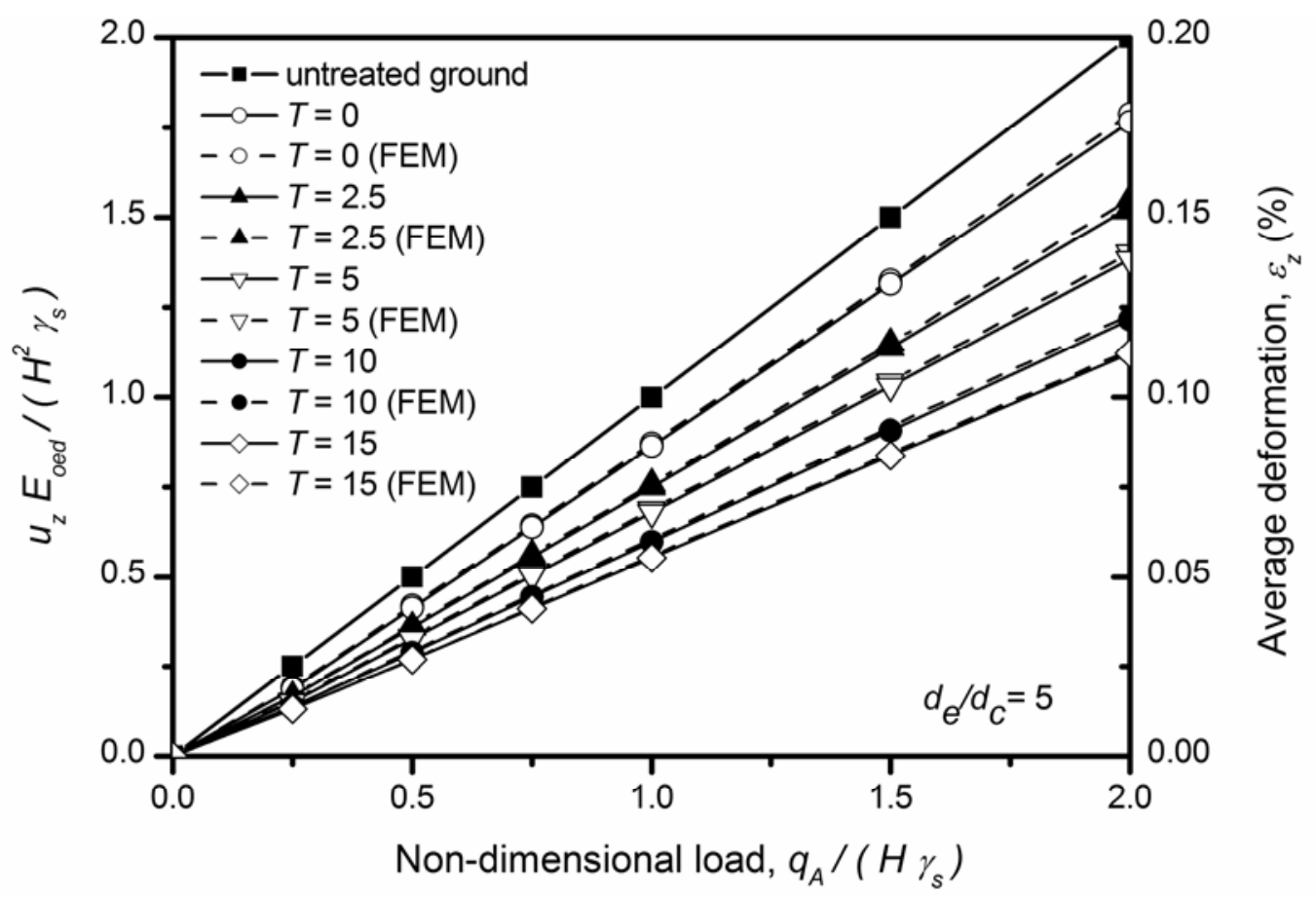

Fig. 3. 


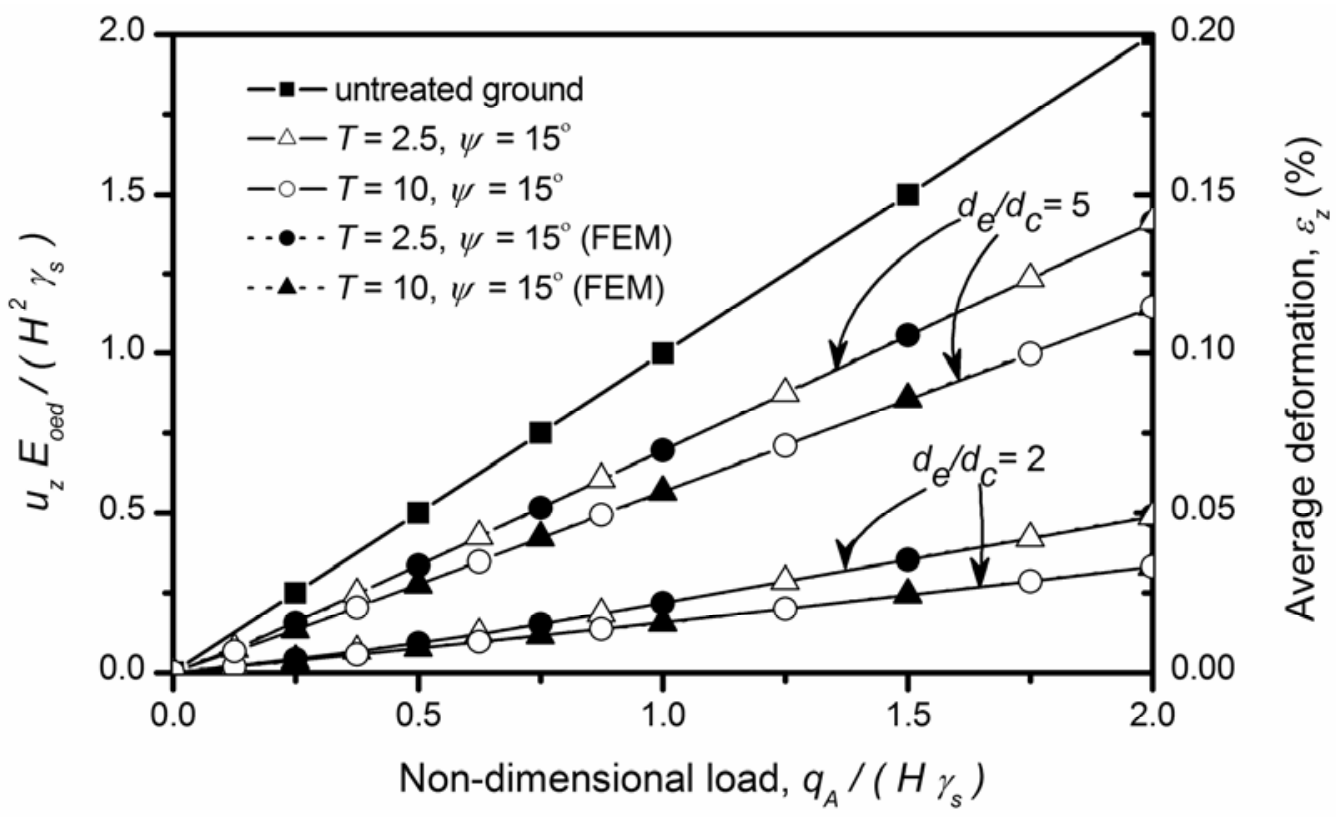

Fig. 4. 


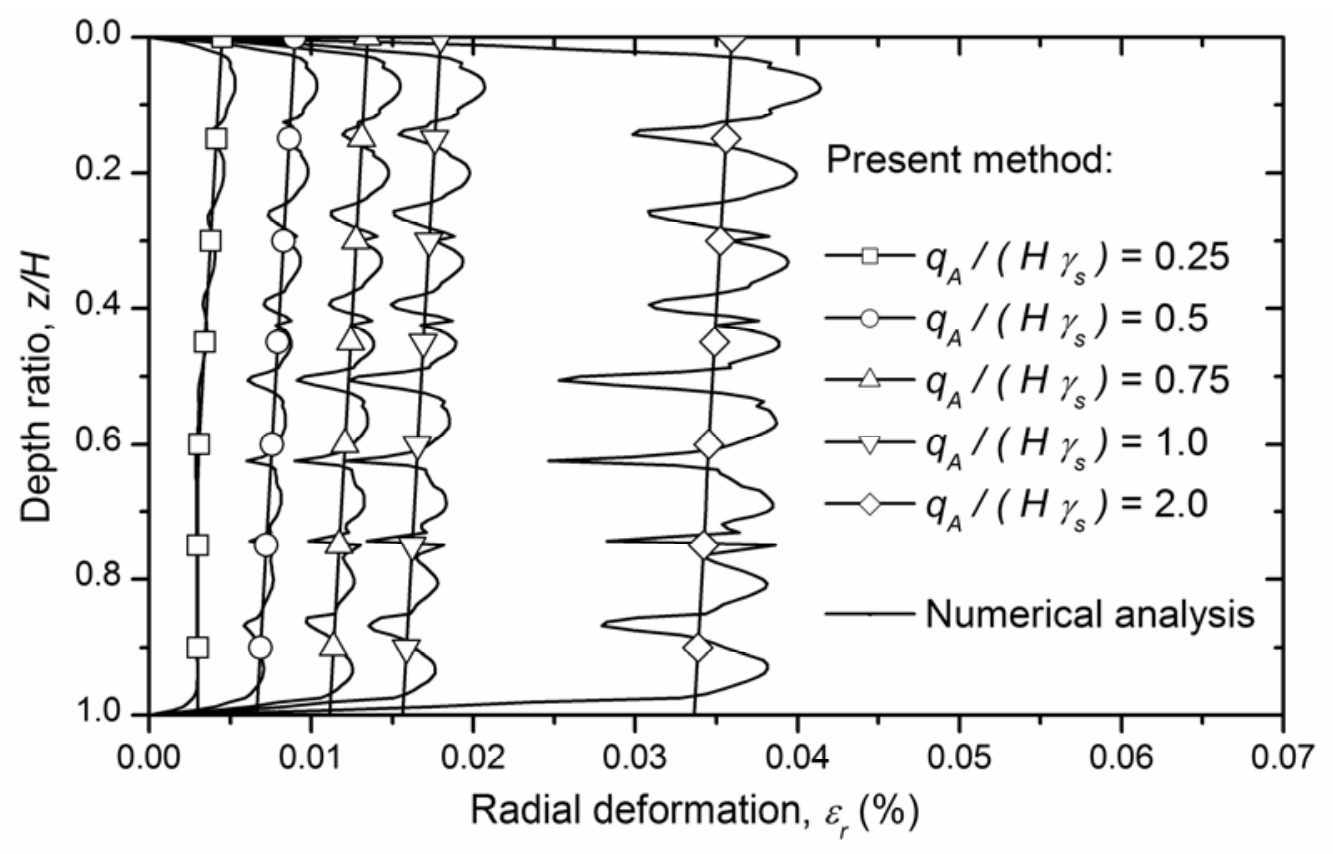

Fig. 5. 


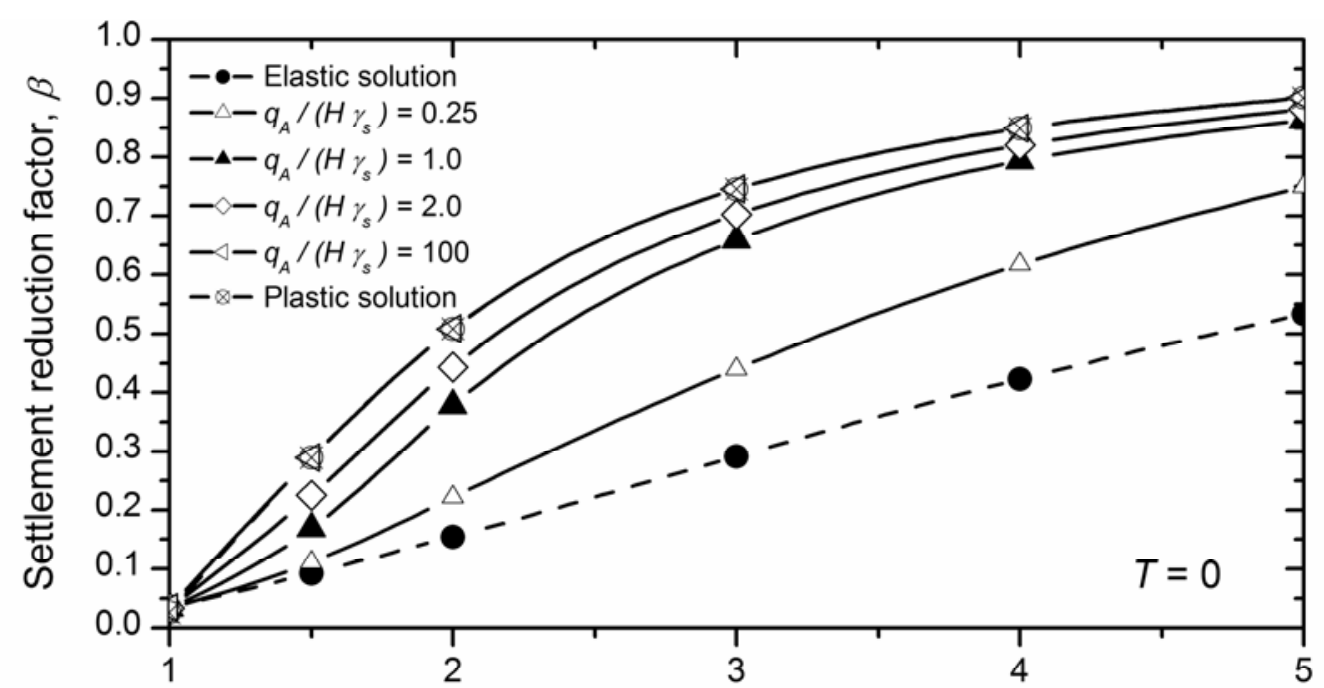

Column spacing ratio, $d_{e} / d_{c}$

Fig. 6. 


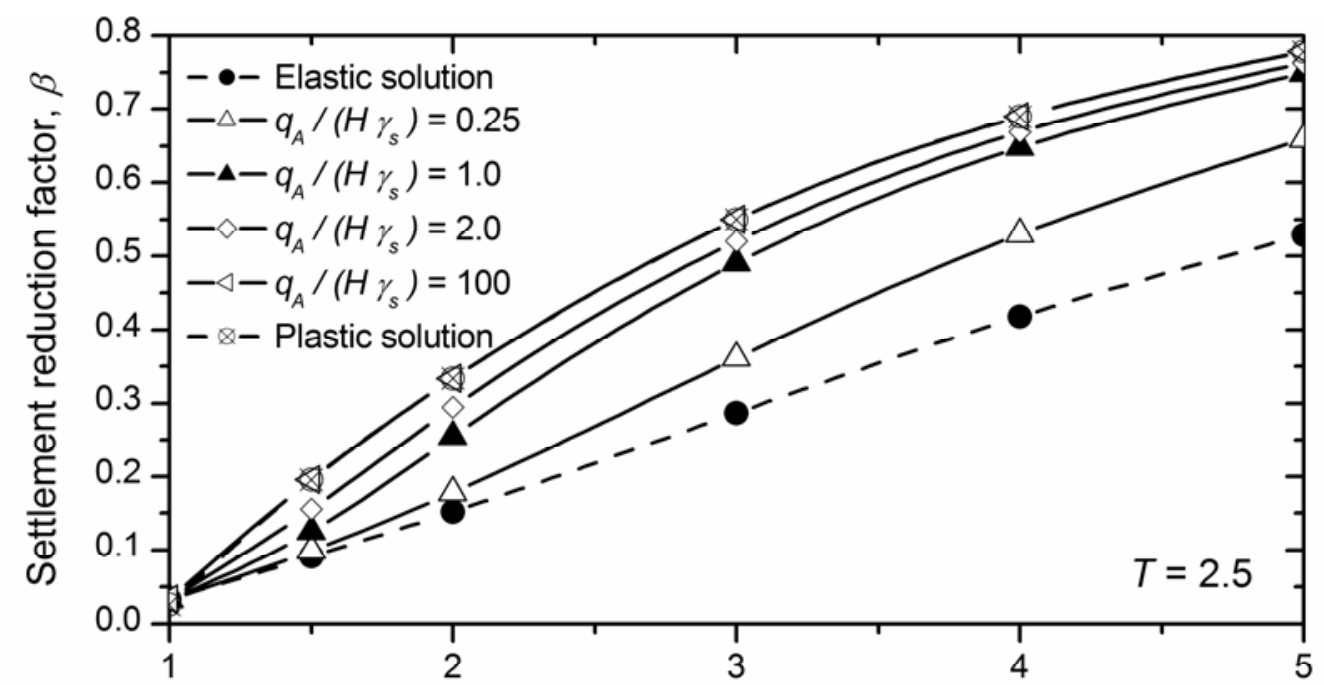

Column spacing ratio, $d_{e} / d_{c}$

Fig. 7. 


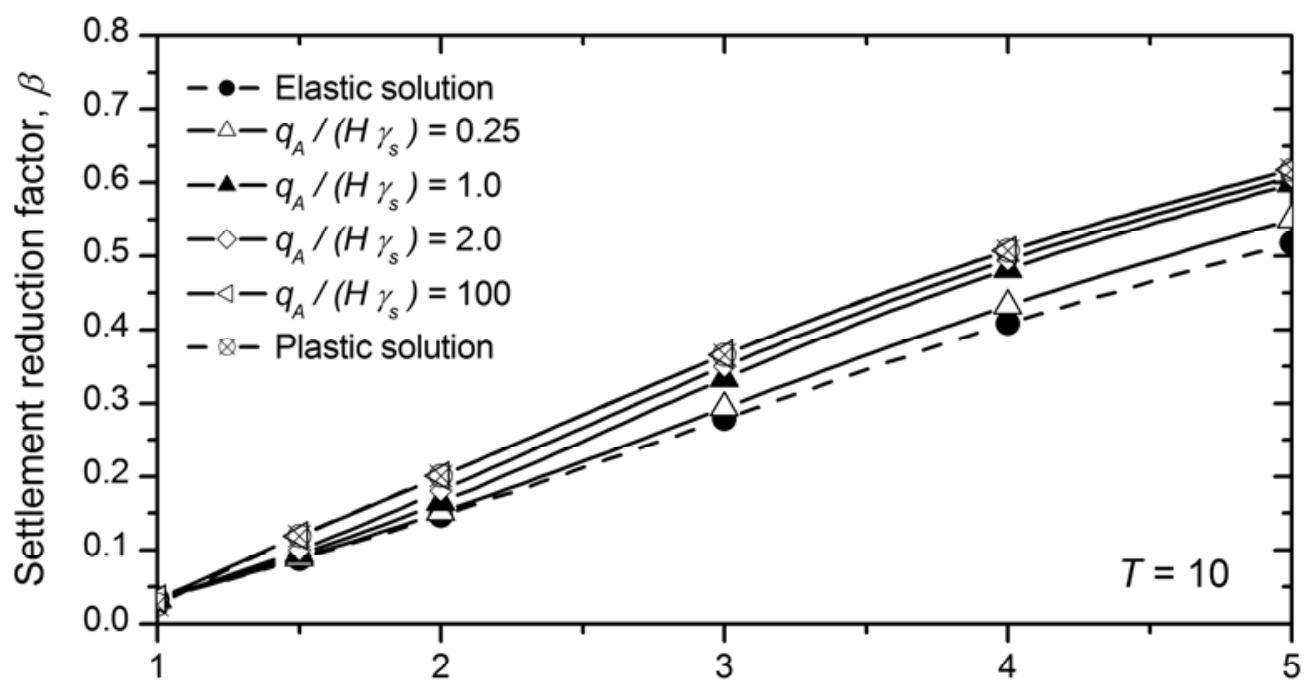

Column spacing ratio, $d_{e} / d_{c}$

Fig. 8. 


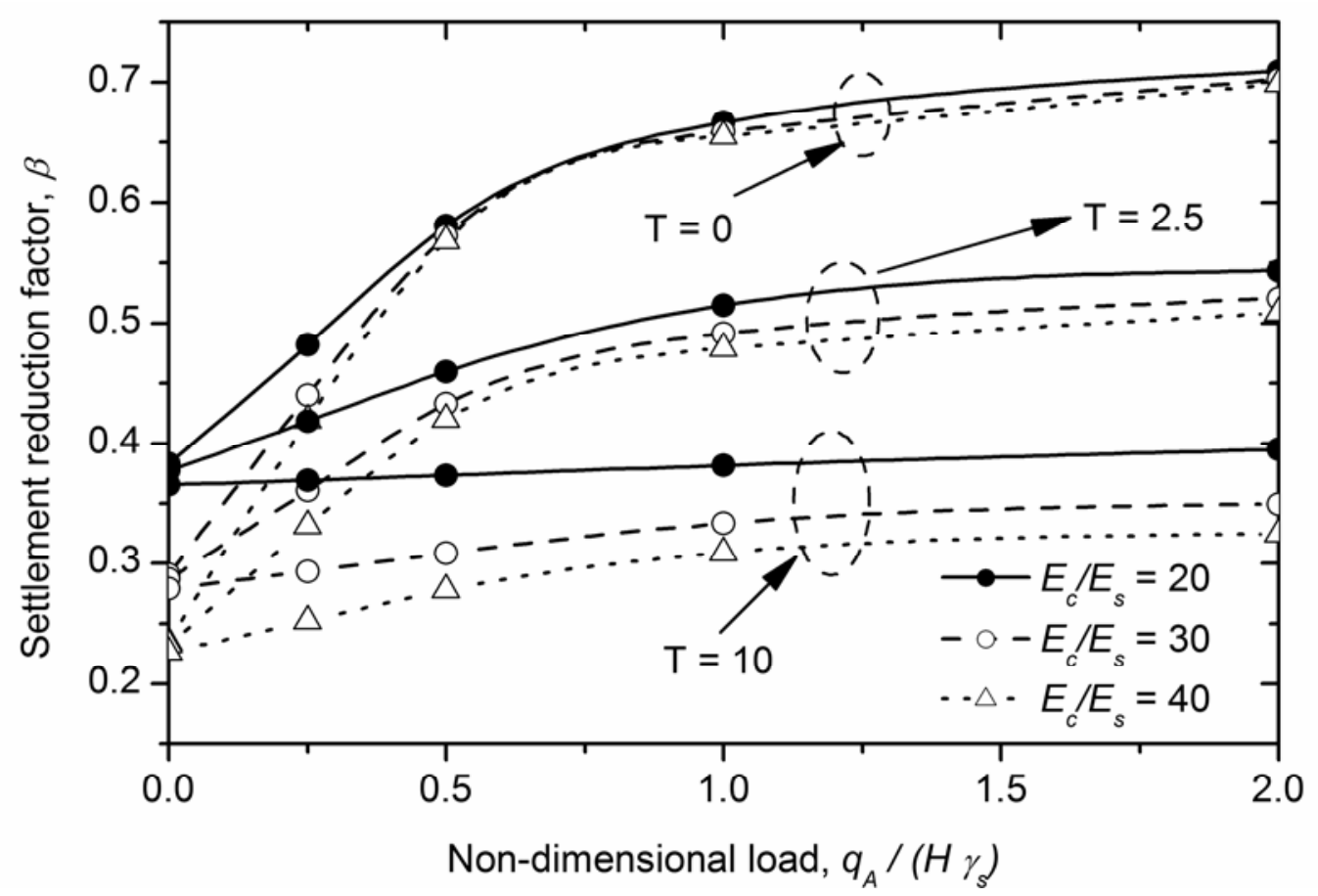

Fig. 9. 


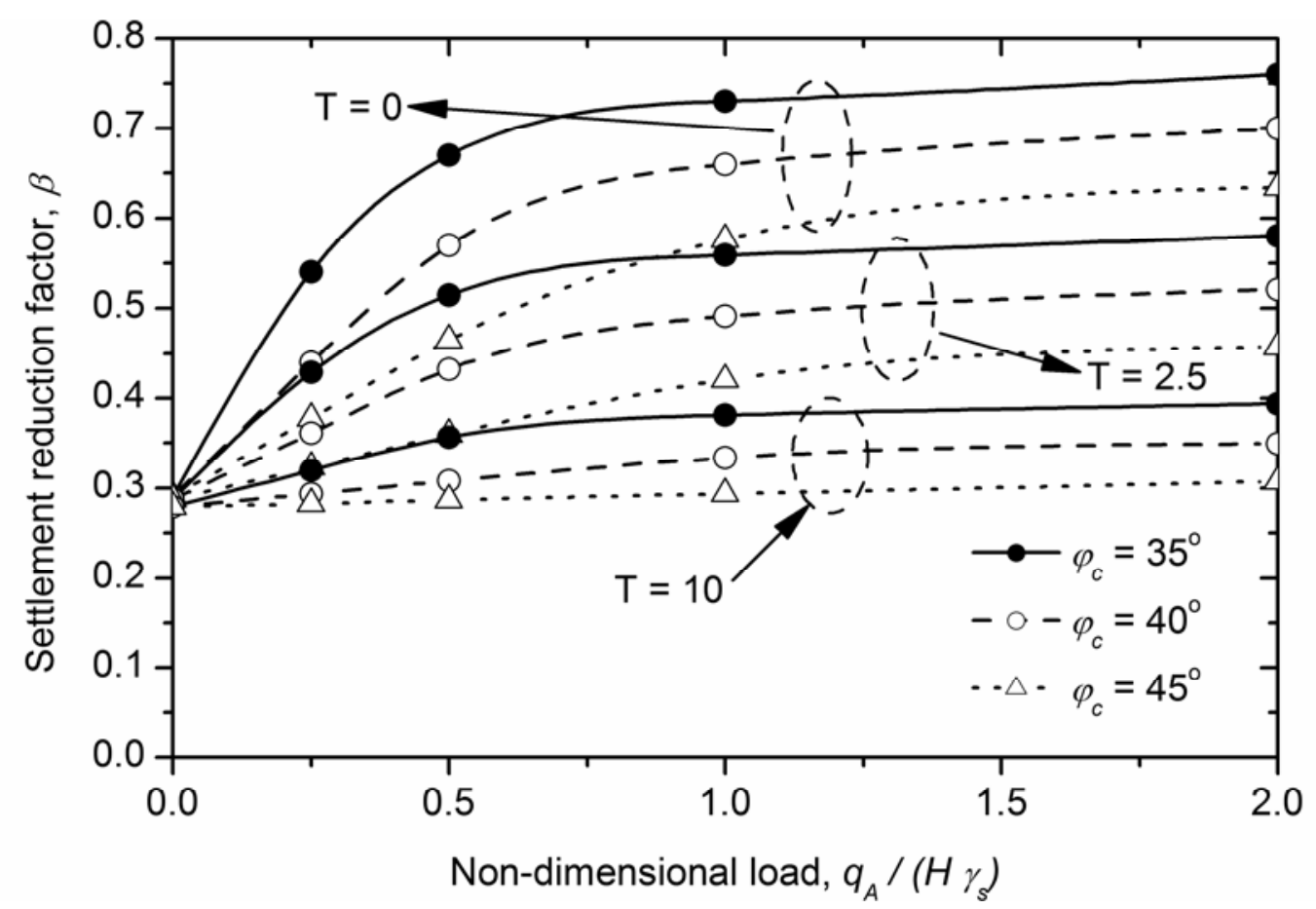

Fig. 10. 


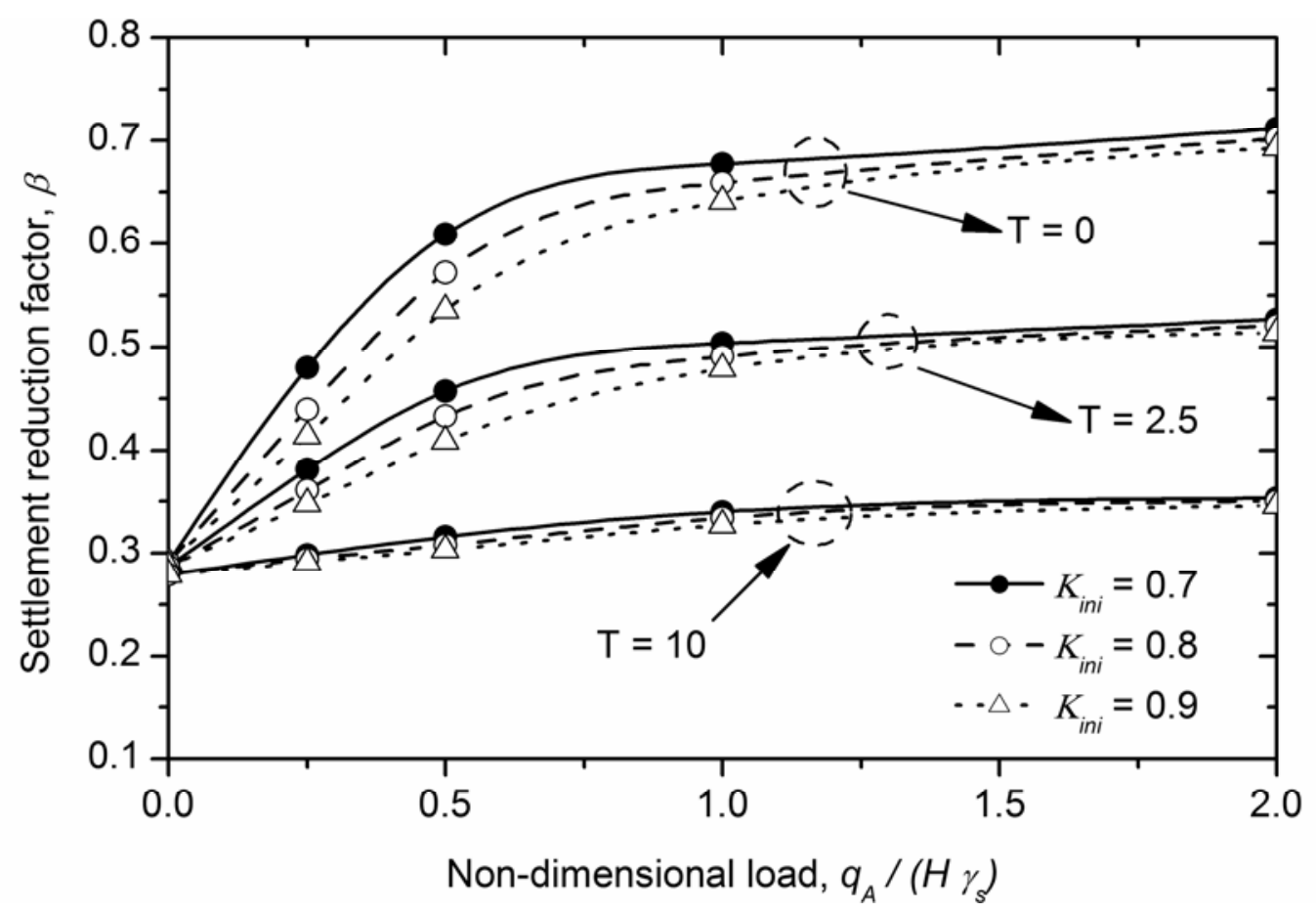

Fig. 11. 


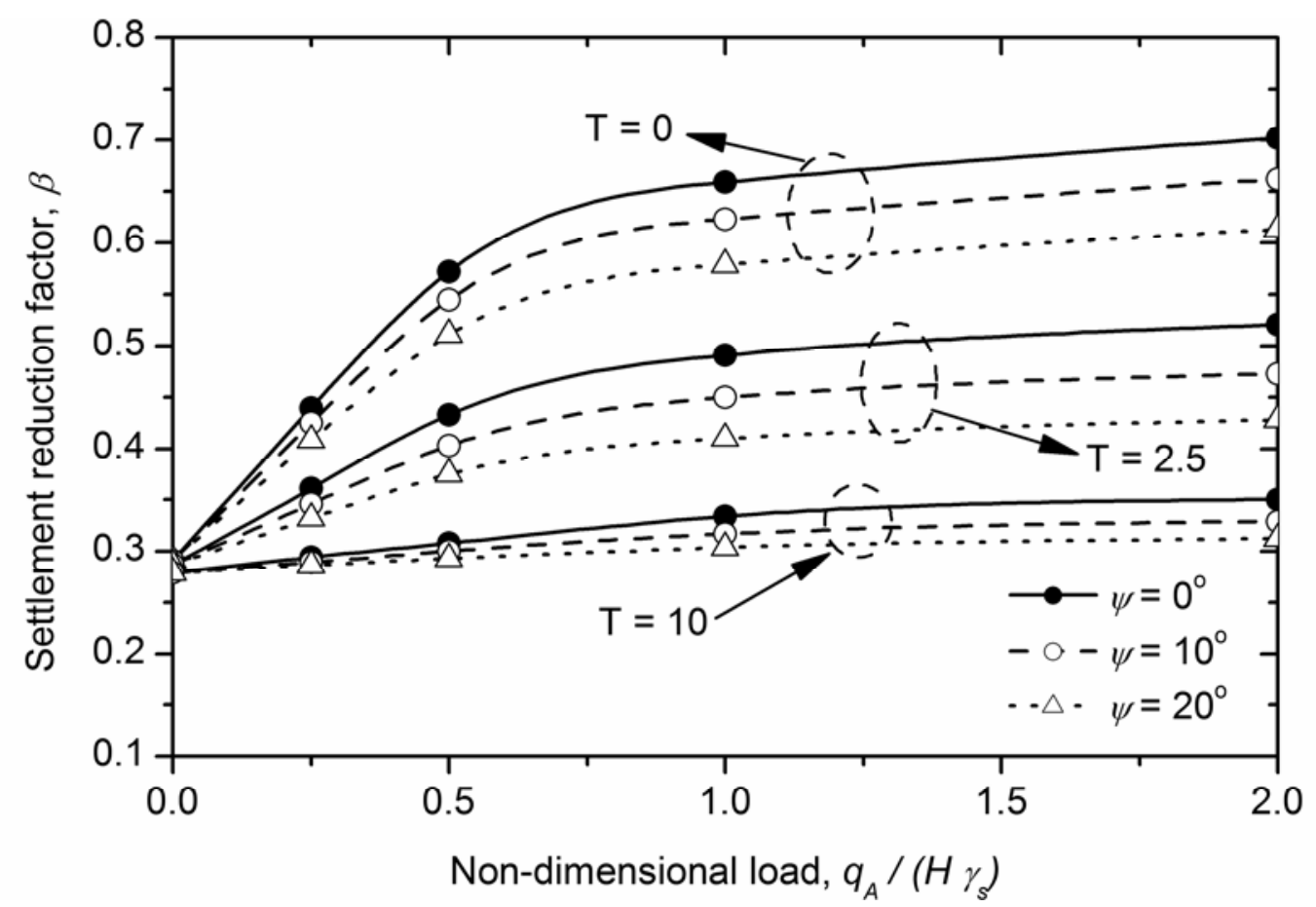

Fig. 12. 


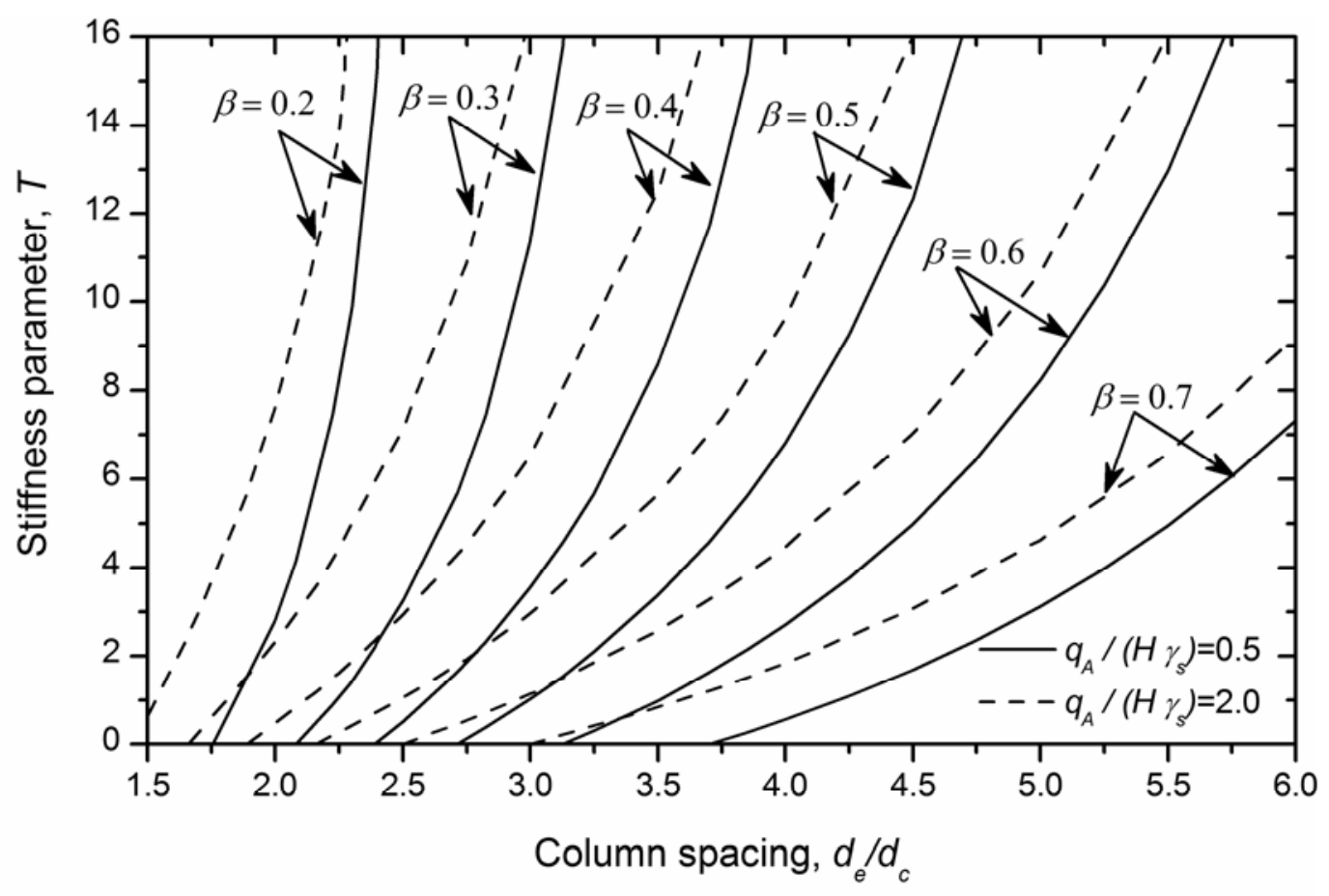

Fig. 13. 


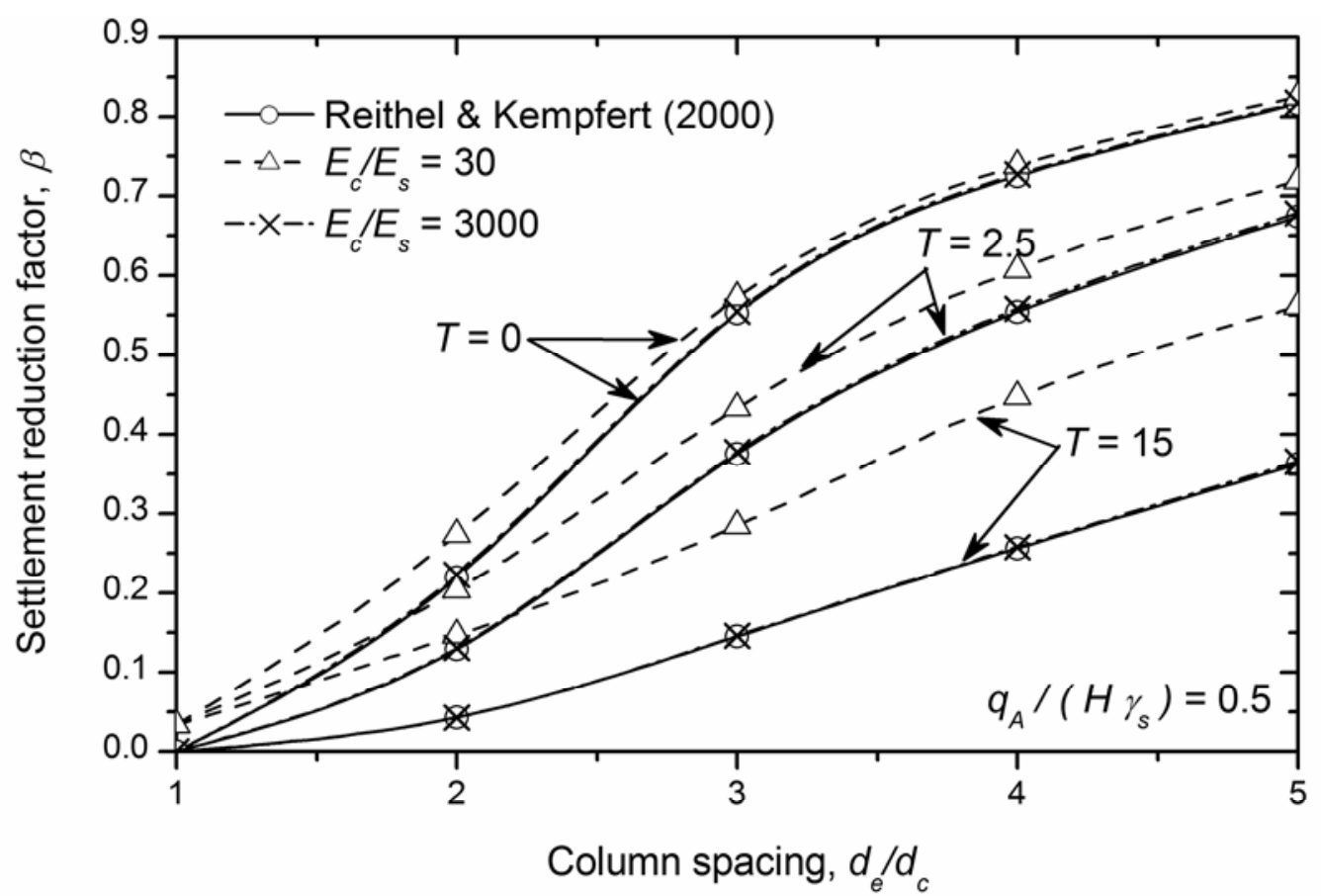

Fig. 14. 


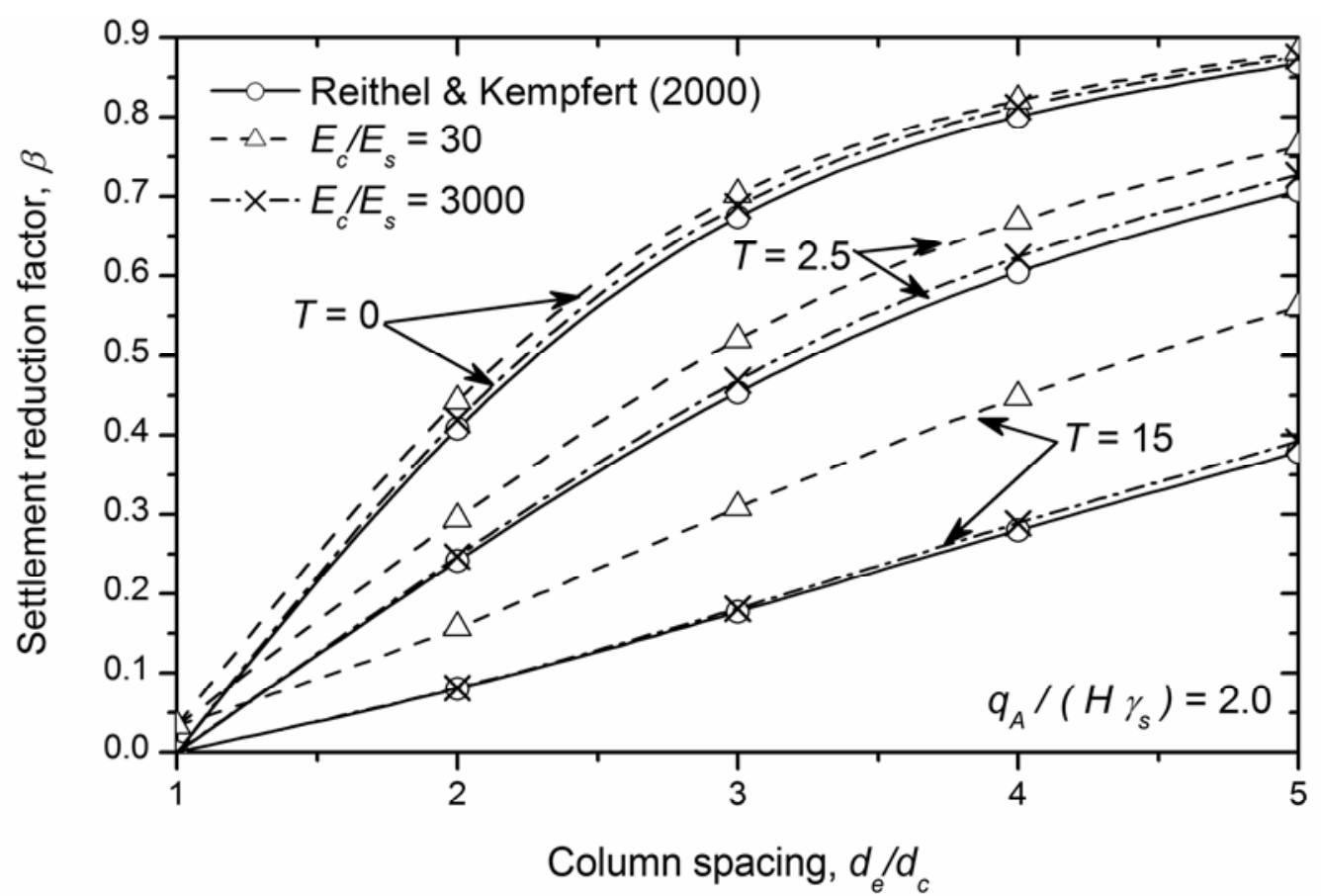

Fig. 15. 